\title{
EL SESEO ENTRE ANDALUCÍA Y AMÉRICA *
}

\author{
Juan A. Frago Gracia \\ Universidad de Sevilla
}

1. Es ya copiosa la bibliografía que sobre la historia del seseo andaluz ${ }^{1}$ existe en estos momentos, así como sobre el desarrollo de este fenómeno fo-

* El texto de este estudio es básicamente el mismo que presenté al Tercer Simposio de Lengua Española (Las Palmas, 29 oct. a 1 nov., 1984) y en él he introducido rectificaciones de detalle nada más, con algún añadido documental de pequeña entidad para lo que hoy podría aducir en este terreno. En cuanto a la bibliografía, no es mucho lo que en los últimos años ha visto la luz sobre la cuestión que trato, pero de ciertas monografías recientes sí me hago eco, no así de la de J. Mondéjar, "Disquisiciones histórico-críticas y metodológicas sobre la interpretación de los datos en el estudio del seseo", publicada en la $R L i R, 49,1985$, págs. 271-286, y en las Actas del I Congreso Internacional sobre el Español de América, San Juan de Puerto Rico, 1987, págs. 275-288. Pero no porque disienta de los puntos de vista de este autor en lo tocante al análisis de las fuentes textuales, sino porque la documentación novedosa que aporta, relativa a un corpus sevillano de 1302, no va acompañada de la correspondiente mención archivística. Me comunica mi colega el medievalista González Jiménez que se trata de un manuscrito de la Biblioteca Nacional no original, sino copia posterior, y confío en que el Dr. Mondéjar aclarará este extremo en su "Edición, léxico y análisis grafemático, fonético y fonológico del Ordenamiento Portuario de Sevilla de 1302", de próxima aparición en la Miscelánea de homenaje para Germán Colón.

1 Véanse, entre otros, los estudios de A. Alonso, "Formación del timbre ciceante en la $c-z$ española", $N R F H, \mathrm{~V}, 1951$, págs. 121-172 y 263-312; "Historia del ceceo y del seseo españoles", Thesaurus, ICC, VII, 1951, págs. 111-200; "O çę̧ear cigano de Sevilla, 1540", RFE, XXXV, 1952, págs. 1-5: en buena medida recogidos en su obra De la pronunciación medieval a la moderna en español, Madrid, Gredos, I, 1967, 2. ${ }^{a}$ ed.; II, 1969. Y también M. Alvar, "A vueltas con el seseo y el ceceo", Romanica, V, 1972, reeditado en Introducción plural a la Gramática Histórica (VV. AA.), Madrid, Editorial Cincel, 1982, págs. 130-144; D. Catalán, "El çeçeo-zezeo al comenzar la expansión atlántica de Castilla", Boletim de Filologia, XVI, 1956-1957, págs. 306-334; Génesis del español atlántico. Ondas varias a través del océano, Universidad de La Laguna, 1958; R. Lapesa, "Sobre el ceceo y el seseo andaluces", Estructuralismo e Historia. Miscelá- 
nético en tierras americanas ${ }^{2}$, producción científica por lo general realizada bajo el condicionamiento de la vieja controversia que gira en torno a la aceptación o el rechazo del andalucismo entendido como determinante base lingüística del español americano en su etapa inicial. No voy a ocuparme aquí de revisar las distintas opiniones que sobre el particular se han formulado -otros lo han hecho antes ${ }^{3}$-, aunque sí me manifestaré partidario del punto de vista que sostiene que en la configuración de las hablas hispanoamericanas jugó un papel de primera importancia el componente dialectal propio de la Andalucía occidental, que llegó al Nuevo Mundo con el hablar de los primeros colonizadores, en muy apreciable porcentaje de la mencionada procedencia peninsular.

No por conocido dejaré de referirme al Mapa de la "Emigración provincial a América (1493-1519): análisis de 5.481 colonizadores de origen determinado o aproximadamente determinado" que diseñó $\mathrm{P}$. Boyd-Bowman y en el cual es Sevilla la única circunscripción territorial que sobrepasa con mucho el millar de emigrados a las Indias, con un total de 1.259, a gran distancia de las que le siguen en aporte humano para el proceso de colonización, a saber, Huelva y Badajoz, con 439 y 440 viajeros, respectivamente: muy lejos quedan las cantidades correspondientes a otras áreas, con índices mínimos de participación para el Reino de Granada, el resto del tercio oriental de la Península y, en el extremo opuesto, Galicia. Comentando los mencionados datos, el citado hispanista norteamericano concluía, de esto hace ahora

nea Homenaje a André Martinet, I, Universidad de La Laguna, 1957, págs. 67-94, reeditado en Estudios de historia lingüística española, Madrid, Colección Filológica Paraninfo, 1985, págs. 249-266; "El andaluz y el español de América", Presente y futuro de la lengua española, II, Madrid, Ediciones Cultura Hispánica, 1963, págs. 173-182, asimismo en Estudios de historia lingiiistica española, págs. 267-282; R. Menéndez Pidal, "Sevilla frente a Madrid. Algunas precisiones sobre el español de América", Miscelánea Homenaje a André Martinet, III, 1964, págs. 99-165.

2 María Beatriz Fontanella de Weinberg, Aspectos del español hablado en el Río de la Plata durante los siglos XVI y XVII, Bahía Blanca, 1982; El español bonaerense. Cuatro siglos de evolución linguiistica (1580-1980), Buenos Aires, Hachette, 1987; Delos L. Canfield, La promunciación del español de América, Bogotá, ICC, 1962; Guillermo L. Guitarte, Siete estudios sobre el español de América, México, UNAM, 1983; R. Lapesa, "Sobre el ceceo y el seseo en Hispanoamérica", Revista Iberoamericana, XXI, 1956, págs. 409-416; Claudia Parodi de Teresa, "Para el conocimiento de la fonética castellana en la Nueva España: 1523. Las sibilantes", Actas del III Congreso de la A. L. F. A. L., Universidad de Puerto Rico, 1976, págs. 115-125 ; Elena M. Rojas, Evolución histórica del español en Tucumán entre los siglos XVI y XIX, Universidad Nacional de Tucumán, 1987.

8 Una reciente síntesis bibliográfica sobre la cuestión del andalucismo del español de América se halla en María Teresa Echenique Elizondo, "Los vascos en el proceso de nivelación lingüística del español americano", Revista Española de Lingüistica, X, 1980, págs. 177-188. 
veinte años, con las siguientes palabras: "No pienso exponer aquí en qué aspectos el dialecto castellano de Andalucía pueda haber diferido en el año 1500 del de Castilla la Nueva o la Vieja. Supongamos siquiera que las diferencias hayan sido ligeras. Mi propósito es más bien el de asentar que en cuanto a la colonización del Nuevo Mundo, fue el lenguaje de Sevilla, no el de Toledo o de Madrid, el que estableció las primeras normas" ".

Cada vez estoy más convencido de que la suposición de este autor debe trocarse en certeza absoluta, pero no en los términos de levedad muy matizada con que él la expresaba, pues el despojo documental induce a pensar que la diferenciación dialectal andaluza era ya bastante acusada a comienzos del siglo XVI, al menos en ciertos medios de la comunidad lingüística meridional. De hecho, el mismo Boyd-Bowman habría de fijar después a mediados de la decimosexta centuria la cronología de varios rasgos fonéticos innovadores en tres cartas, fechadas dos en 1568 y una en 1569, de un sevillano emigrado ya adulto a la Nueva España, dado que había cruzado el Atlántico dejando atrás esposa 5 .

1.1. No sería el seseo, ciertamente, la única nota diferenciadora llevada al español americano por los andaluces, puesto que habrá que contar también con fenómenos como los que se derivan del debilitamiento de la /-s/ implosiva, la aspiración / $\mathrm{h} /$ procedente de /f/ latina, el yeísmo y otros relajamientos articulatorios consonánticos, entre ellos el que afecta a la neutralización de las líquidas / $-\mathrm{r},-1 /$, etc. Sin embargo, sólo el seseo es modismo exclusivo de las hablas andaluzas, mientras que los demás que acabo de apuntar se conocen, y han existido desde hace mucho tiempo, en distintas regiones españolas, aunque sea en Andalucía donde adquieren una especial relevancia y cohesión, lo mismo geográfica que social, como puso de relieve M. Alvar ${ }^{\circ}$. Sea como fuere, salvo en el caso de la pronunciación seseosa, españoles nacidos en muy diversos territorios pudieron ayudar a conformar fonéticamente la peculiaridad lingüística americana con los restantes tratamientos que la caracterizan.

4 P. Boyd-Bowman, Indice geobiográfico de cuarenta mil pobladores españoles de América en el siglo XVI (t. I, 1493-1519), Bogotá, ICC, 1964, pág. xxIv. En el estudio de este investigador que cito en la nota siguiente se produce un más claro y acertado acercamiento a lo que es la verdadera antigüedad del dialecto andaluz, según resumo un poco más abajo.

5 P. Boyd-Bowman, "A Sample of Sixteenth Century 'Caribbean' Spanish Phonology", 1974 Colloquium on Spanish and Portuguese Linguistics, Washington, Georgetown University Press, 1975, págs. 1-11.

- M. Alvar, "Hacia los conceptos de lengua, dialecto y hablas", $N R F H, \mathrm{XV}, 1961$, págs. 58-59. Artículo reeditado en La lengua como libertad, Madrid, Ediciones Cultura Hispánica, 1982, págs. 56-65. 
1.2. Si, en expresión feliz de García de Diego, nuestra lengua es un "complejo dialectal" ", no sólo resulta obligado describir las similitudes y desemejanzas en el español de hoy, así como las interacciones actuantes entre sus diferentes variedades diatópicas y niveles socioculturales; será conveniente también explicar históricamente cómo se ha llegado al actual estado de cosas. $\mathrm{Y}$, en este sentido, preciso será reconocer que los estudiosos del español somos particularmente afortunados, ya que, aparte de la pervivencia de unas hablas tan cargadas de historia como las sefarditas y las reminiscencias dialectales del norte de la Península, podemos observar la formación de dos grandes espacios de innovación lingüística, el andaluz y el hispanoamericano - $-\mathrm{y}$, en medio, el canario con afinidades del uno y del otro-, dándose la notable circunstancia de que en ambos casos el distanciamiento dialectal se ha producido en época plenamente documentada. Las dos realidades lingüísticas tienen en común, además, el haberse originado como consecuencia de sendos procesos de colonización en los que intervinieron grupos humanos de muy distintas naturalezas.

2. El criterio grafémico seguido para demostrar el ensordecimiento de las sibilantes sonoras en la España norteña debe ser válido asimismo para verificar la existencia o la inexistencia de ese fenómeno, y de los que con él se encuentran relacionados, en el mediodía peninsular. Pues bien, del análisis filológico de textos medievales andaluces se desprenden hechos lingüísticos sin duda sorprendentes, que se compaginan mal con las enseñanzas extraídas de la interpretación de corpus literarios o de las afirmaciones de tratadistas imbuidos de una concepción purista y tradicional de la norma del hablar culto.

La cronología que sobre los inicios del reajuste de las sibilantes en las hablas andaluzas había fijado A. Alonso ha sido anticipada en mucho por investigaciones de otros estudiosos ${ }^{8}$, pero el expurgo de fuentes del más diverso signo localizadas en zonas meridionales retrotrae aún más la comprobación de toda una serie de fenómenos evolutivos. $\mathrm{Y}$ es necesario advertir que estas cuestiones cronológicas entre otras cosas tienen la virtud de poner en tela de juicio doctrina tan asentada como es la de un reajuste fonológico entendido en su difusión social como una propagación paulatina y

7 V. García de Diego, "Dialectalismos", RFE, III, 1916, págs. 301-318; "E1 castellano como complejo dialectal y sus dialectos internos", RFE, XXXIV, 1950, páginas $107-124$.

8 R. Lapesa encuentra unos pocos ejemplos andaluces de confusión entre $s$ y $z$ del año 1419 y proporciona casos de equivalencias de $s s-s$ con $c-z$ ya más abundantes a partir de mediados del siglo xv: "Sobre el ceceo y el seseo andaluces", págs. 252-253 (cito por Estudios de historia lingiiistica española). 
continuada de norte a sur. La aceptación de este principio debe hacerse hoy, creo, con las máximas reservas.

2.1. En otro trabajo he dado testimonios de la igualación entre /s/ y /z/ a partir de 1386 en textos andaluces, así como ejemplos de confusiones grafémicas correspondientes a las cuatro sibilantes $/ s, z, \hat{s}, \hat{z} /^{\circ}$. Sin embargo, a poco que se profundice en el despojo documental, la antigüedad de tales cambios se revela siempre mayor. En un solo corpus he atestiguado los siguientes hechos, con dataciones que pongo entre paréntesis ${ }^{10}$ :

1. Pérdida de la distinción sonoridad/sordez en los elementos fonológicos :

a) /̌̀, ž/: enaxenar (1348), Almojafar-Almoxaffar (1346-1348) ${ }^{11}$.

b) / $\hat{\mathrm{s}}, \hat{\mathrm{z}} /$ : Çezilla-Çeçilla (1314-1315), raşón (1346) ${ }^{12}$.

c) /s, z/: abadessa-abadesa (1342) ${ }^{13}$; cassas (1326, 1329, 1332, $1353)^{14}$; cossa-cosa $(1345,1346,1353)^{15}$; misyones 'missiones (gastos)' (1375) ${ }^{16}$; posseo, posseerla-poseedoras, posesión

- Juan A. Frago Gracia, "De los fonemas medievales /s,$\hat{z} /$ al interdental fricativo / $\$ /$ del español moderno", Philologica hispaniensia in honorem M. Alvar, II, Madrid, Gredos, 1985, págs. 205-216. Los ejemplos de confusión entre $s s-s$ y $c-z$ que en este trabajo aduzco se atestiguan desde el año 1405.

10 Todas las atestiguaciones que siguen están tomadas de María A. Vilaplana, La colección diplomática de Santa Clara de Moguer. 1280-1483, Sevilla, Servicio de Publicaciones de la Universidad de Sevilla, 1975. La totalidad de los textos que utilizo de esta excelente paleógrafa responde a transcripciones de documentos originales. Cuando se trata de dobletes del tipo cossas-cosas, las fechas correspondientes a cada una de las variantes se separan también con un guión.

11 Ibid., docs. 36, 39.

12 Ibid., docs. 5, 7, 36. Aunque en castellano medieval razón se escribe por lo general con -z-, se encuentran esporádicos ejemplos de raçón, que en el $D E C H$ se atribuyen a cultismo, es de suponer que ortográfico, sin que se explique el porqué de tal atribución: J. Corominas y José A. Pascual, Diccionario crítico etimológico castellano $e$ hispánico, Madrid, Gredos, 1980 y sigs., s. v. En el doc. 4 de esta colección diplomática, del año 1313, el nombre del personaje femenino arriba citado como Çezilla-Çeçilla aparece con la variante Seziella, descubriéndose en él la alternancia de $c$ y $s, y$ otros casos de confusión grafémica los constituyen los dobletes fazer-facer (1435) y juyçiojuyzio de los docs. $137,176$.

13 Ibid., doc. 28.

14 Ibid., docs. 15, 17, 18, 50. De forma regular se halla cassas en estos cuatro documentos, en los que dicha grafía se registra numerosas veces; constante es, sin embargo, el uso de casas en el doc. 13, del año 1322.

15 Ibíd., docs. 34, 36, 50. El doblete se verifica en los dos primeros textos; el tercero registra únicamente cossas, con tres atestiguaciones.

16 Ibíd., doc. 72. Cultismo tomado del lat. mis sio, en época medieval común- 
(1351) ${ }^{17}$; possier 'pusiere' (1346) ${ }^{18}$; quissiéramos, quissiéredes (1331), quissierdes-quisierdes (1345), quissierdes, quissiere $(1353)^{10}$; vsso, ussual (1353) ${ }^{20}$.

2. Equivalencias grafémicas de carácter unificador relativas a las sibilantes /s, z/ y / $\hat{\mathrm{s}}, \hat{\mathrm{z}} /$ :

a) Empleo de $s$ por $c$ : hesebşión 'excepción' (1352), exssebçiones (1353), exebçión (1430) ${ }^{21}$, juysio (1478) ${ }^{22}$.

b) Uso de $c$ por $s$ : ençenço 'censo' (1425), ençienço íd. (1449) ${ }^{28}$; ecleçiásticas $(1430)^{24}$.

2.2. En el primer tercio del siglo XVII son ya verdaderamente abrumadoras, desde el punto de vista numérico, las noticias de este tipo que proporciona la documentación no literaria andaluza. En el caso del seseo, el arraigo social de esta innovación fonética debía ser tan grande que incluso se refleja en textos pertenecientes a la alta cultura literaria. A este respecto, José Manuel Blecua ha notado que en los manuscritos poéticos quevedescos

mente con -ss-, igual que en esta colección diplomática. Reaparece misiones en el doc. 124, del año 1430.

17 Ibid., doc. 47.

18 Ibid., doc. 36.

10 Ibíd., docs. 21, 34, 50. El resultado etimológico con -s- abunda en otros documentos.

20 Ibid., doc. 50.

21 Ibíd., docs. 48, 50, 124. Además, esebçión (1397, 1472), esepçión (1400, 1406), exsçebçión (1478), en los docs. 91, 93, 97, 177, 181.

22 Ibid., doc. 181.

23 Ibid., docs. 119, 159. En el primer texto las seis veces que se utiliza esta palabra es con la grafía ençenço; en el segundo hay un ençienço, un ençenso, otro ynçienso y tres ynçenso. Variantes como ençienso y censo son frecuentes en muchos documentos de este corpus.

24 Ibid., doc. 124. No se crea, sin embargo, que los datos hasta aquí consignados confieren una especial singularidad al corpus al que pertenecen. Sin mencionar los casos de equiparación de $b-v$, por un lado, y de $s s-s$, por otro, innumerables en diferentes fuentes andaluzas del siglo xIV, señalaré estas otras verificaciones documentales: omenaxe (1347), fessieron 'hicieron' (1347), neçesario-nezesaria (1443), Medina Ciidonia (1467, 1484), Çiguença 'Sigüenza' en dos ocasiones (1470): María L. Pardo Rodríguez, Huelva y Gibraleón (1282-1495). Documentos para su historia, Huelva, 1980, docs. 24, 25, 80, 85, 87, 88, 90. También Çuárez 'Suárez', rezes 'reses' (h. 1550): María C. Quintanilla Raso, "Ordenanzas municipales de Cañete de las Torres (Córdoba). 1520-1532", Historia, Instituciones y Documentos, II, Sevilla, 1975, págs. 483, 510, 512. Y, finalmente, possesión-possessión (1386), rraysses (1405), ambos de Jaén: Paleografía de Andalucía oriental. Transcripciones, edición dirigida por Josefina Mateu Ibars, Granada, 1977, págs. 160, 162, grafías todas ellas comprobadas en láminas facsimilares. 
cuando el copista es andaluz se deslizan "errores" de tan específica naturaleza como son las cacografías lus, reconoscas, condisión, lucitano 'lusitano', paresca, abrazado 'abrasado' y caucó 'causó' de la comedia de hacia 1627 Cómo ha de ser el privado ${ }^{25}$, o la que se produce en el Entremés de los enfadosos, escrito antes de 1624, cuya copia B de la Biblioteca Colombina trae invariablemente Zaraça o Zaraza donde el Ms. A pone Carasa ${ }^{26}$. Es claro que los mismos hechos tienen lugar, sólo que de una manera mucho más acusada, en corpus cuyo contenido pudiera calificarse de práctico, así, entre otros muchos, los libros de las cofradías sevillanas, de los que uno, que se fecha en 1696 y que se conserva en la iglesia de Santa María la Blanca, antigua sede de la Hermandad del Sagrado Lavatorio de Cristo y Ánimas Benditas del Purgatorio, ya en su portada descubre las formas hasen y empiesa ${ }^{27}$.

Por supuesto, cuanto más vulgares sean los escritos considerados tanto mayor será la frecuencia con que en ellos surjan las peculiaridades fonéticas de carácter regional o aquellas otras que denotan la identificación del corpus en cuestión con una norma lingüística de bajo nivel cultural. Esto se verifica en un cartel impreso como exvoto en Utrera el año 1828, que reza así : "Hallándose Domingo Martín en la plaza del Altosano viendo jugar un Toro de cuerda, tubo la desgracia de que lo cojiese, haciéndole una muy profunda y mortar herida, de la cual sanó perfectamente por la ynterceción de N. M. y Sra. de la Consolación, a quien fervorosamente lo encomendó su muger María Tirado" ${ }^{28}$. En tan breve texto hay, según puede comprobarse, dos ejemplos de indistinción entre $s$ y $c$, junto a uno de $-r$ por $-l$.

Es preciso tener en cuenta, sin embargo, que por lo general el aspecto cualitativo - mejor o peor formación intelectual de quien escribe- se traduce en términos cuantitativos, por lo que se refiere a la abundancia relativa de grafías que se apartan de las pautas marcadas por la ortografía oficial, pero que, asimismo, la conciencia purista de un determinado autor no excluye, sin más, la comisión de tales faltas, en el contexto sociolingüístico y dialectal al que estoy aludiendo; incluso, aunque poco numerosas, tendrán una relevancia especial para el historiador de la lengua. Bien significativa es en

25 Francisco de Quevedo, Obra poética, ed. de José Manuel Blecua, Madrid, Editorial Castalia, 1981, IV, págs. 149, 190.

28 También opina Blecua que el copista del manuscrito de la Colombina fue andaluz (ibíd., pág. 123). Y están, además, los numerosos ejemplos de elisión de $-s$ final y de ultracorrecciones ocurridas con dicha letra en esa posición, cuya explicación dejo para otro estudio.

27 Titulado Libro en que se sientan los cauildos que se hasen en las Cofradias del Santisimo Sacramento, ánimas venditas del Purgatorio ...

28 Reproducción fotográfica en el $A B C$ de Sevilla, 29-V-1983, pág. 15. 
este sentido la obrita de un maestro de primeras letras gaditano, Antonio Balbina Lozano, redactada hacia 1809 , en la que hay un explícito acatamiento al magisterio académico, rotundamente expresado en estas palabras: “ ¿Se podrán encontrar reglas más finas, ni que más gusto dé leerlas por su eloquente y puro castellano, que las de mi madre la Real Academia? Es difícil. En ella están definidas todas las dudas y se encuentra la perfección de la pronunciación y escritura castellana" ${ }^{20}$. Pues bien, a pesar de que este pedagogo, antiguo profesor de Ortografía en su Cádiz natal, aconseja la distinción de $c-z$ y $s$ para diferenciar "el significado por las letras" en casos como cincuenta/sin cuenta, cegar/segar, cocer/coser, loza/losa, él mismo, adicto a las normas ortográficas de la Real Academia y hasta admirador incondicional de los modelos fonéticos castellanos no andaluces, es incapaz de evitar que su idiolecto lo traicione con las grafías dies, ensima, latigaso, lus, pes 'la pez' ${ }^{30}$.

2.3. Es el Archivo de Protocolos de Sevilla centro de documentación fundamental para el establecimiento de la historia del andaluz occidental, y no ha sido hasta ahora utilizado por los estudiosos del español ${ }^{31}$. Aduciré a continuación algunas atestiguaciones sacadas de varios legajos del primer tercio del siglo XVI, es decir, de las fechas en que al otro lado del Atlántico se está cimentando la base del español americano. Advierto que en ningún momento he recurrido a ejemplos con "ese sigma" para soslayar los problemas añadidos de interpretación fonética que ese signo conlleva, y que los hechos grafémicos señalados sólo constituyen un sumario espigueo en el ingente acervo de datos históricos que estas fuentes notariales contienen. En cualquier caso, la información que aquí aporto es una corroboración más de la existencia del seseo en el Reino de Sevilla por esa época.

Año 1501 : dies, fiso, justisia, riso 'rizo', Sanches, vesino ${ }^{32}$.

29 M. Alvarez García, "Sobre la enseñanza de la lengua española en Andalucía a principios del s. xix", Archivo Hispalense, núm. 203, 1984, págs. 168-169. El manuscrito, conservado en la Biblioteca Universitaria de Sevilla, estaba destinado a una publicación que truncarían los avatares de la Guerra de la Independencia. El autor formula, entre otras del género, esta crítica: "no saldrán los andaluces de su mala pronunciación y, por consiguiente, la ignorancia en la escritura permanecerá" (pág. 171).

30 Ibíd., págs. $170,174$.

31 Por supuesto que otros interesantes archivos se hallan desparramados por toda Andalucía occidental. En la misma Sevilla hay varios de gran valor, entre ellos el municipal, el catedralicio y la Biblioteca arzobispal, dotada de abundantes manuscritos y desde hace muy poco reabierta al público.

32 Archivo Histórico de Protocolos de Sevilla (AHPS), Oficio 5..$^{\circ}$, legajo 1.501, fols. $1,2,5,59,64,160,161,196$. Documento la forma dies dos veces y en tres ocasiones la grafía vesino, pero realmente esta última se registra con extraordinaria profusión en cualquier legajo del XvI; en lo sucesivo no aludiré más a las repeticiones de determi- 
Año 1507: conosco, consiençia, establesco, nesezidad, quizo, sarpó, vesino ${ }^{33}$.

Año 1510: dies, fiso, fisieron, nasimjento, vesino ${ }^{34}$; alguasil, Aluares, dies, vesjno ${ }^{85}$; rrasón $^{38}$; dies, vesino ${ }^{37}$; onse, quinse, vesino ${ }^{38}$; conosco, contradesir, desfaser, desir, dies, faser, fisiere, fiso, haser, hisiere, jueses, juysio, rasón, rasonar, rayses, vesino ${ }^{39}$.

Año 1516: asienda, capitulasión, cláuzula, çobre 'sobre', desisorio, dies, fiso, Hernandes, Isquierdo, tresientas, Vazques, veses ${ }^{40}$.

Año 1518: camizones 'camisones' ${ }^{41}$.

Año 1526: divizión, Fernandes, Gutierres, Hernandes, Lopes, protestasiones, Ramires, Rodrigues, Sanches, Sisilia, Suares, vasyas 'vacías', vesino, Xeres, Ximenes ${ }^{\star 2}$.

Año 1530: almjres 'almirez', arteza 'artesa', frizada 'frisada', Gimenes, ynsidençias, saragueles 'zaragüelles', sustitusjón, vesyno ${ }^{43}$.

nados rasgos grafémicos. Por "oficios" hay que entender notarías, y de ellos se mencionarán los de San Juan de la Palma, Alcaicería de la Seda, Santa Catalina, Barrio del Duque, San Lorenzo y Barrio de Triana (núms. $1 .^{\circ}, 3 .^{\circ}, 4 .^{\circ}, 5 .^{\circ}, 1 .^{\circ}$ y $23 .^{\circ}$, respectivamente).

83 AHPS, Oficio $1^{\circ}$, legajo $1.507-1.508$, fol. 1r y v, delante del $4 .^{\circ}$ cuadernillo empezando por el final. Notario Clemente de la Cuadra.

84 AHPS, Oficio $1 .^{\circ}$, legajo 1.510 , fols. 1, 2, 3, 5 del primer cuadernillo.

85 Ibid., fol. 41 del segundo cuadernillo.

se Ibíd, fol. $67 \mathrm{v}$ del tercer cuadernillo.

37 Ibid., fol. 79 del cuarto cuadernillo.

88 Ibid., fols. 103, 105v, 106 del quinto cuadernillo.

89 AHPS, Oficio $1 .^{\circ}$, legajo 1.510 , libro $\mathrm{V}$ (numerado y dividido en cuadernillos), fols. 1, 2, 4, 12, 16. En estos cinco folios las mencionadas grafías se repiten hasta alrededor de setenta veces, en ocasiones con la densidad que revela este pasaje: "porque pueda haser e desir e rasonar assí en juysio como fuera dél" (fol. 16). Como más adelante diré de nuevo, en esta documentación, igual que en la restante, no se aprecia valor específico alguno para la ese "sigma", que puede encontrarse en cualquier posición en alternancia con la letra de trazado moderno y con la $z$, en palabras como hazer, razón, dezir, lo mismo que se hallará la ese "sigma" en la forma asý (fols. 1r, 2r), tradicionalmente escrita con ss; con ese alta viene conosco.

to AHPS, Oficio 3. ${ }^{\circ}$, legajo 1.516, fols. 71 (papel suelto, $9^{\circ}$ tras el citado folio); 103 (primer papel suelto que sigue a este folio, capitulasión en el segundo papel); 111 (papeles sueltos 2, 6, 11); 192 (papel suelto 13); 311 (papeles sueltos 19, 20) ; 316 (papel suelto 4$)$; 408, 591, 592, 611 .

41 AHPS, Oficio $4 .^{\circ}$, legajo 1.518 , fol. 2 del quinto cuadernillo.

42 AHPS, Oficio $3 .^{\circ}$, legajo 1.526 , fols. 10,16 del cuadernillo primero; 2,16 del cuadernillo segundo; papel suelto tras el fol. 96 ; 109 ; papel suelto tras el fol. 122 ; 176, 217, 229, 231, 241, 278v, 398, 404.

48 AHPS, Oficio $3^{\circ}$, legajo 1.530 , fols. $6,11,14,19 ;$ y los fols. 1-2 del pliego suelto que va ordenado detrás del fol. 186. 
Año 1531: Baltazar-Valtazar, Beatris Ximenes, dibizión, Gutierres-Catalina Gutierres, Hernandes, Peres, porsión, Sanches $\$$.

Año 1534: bensido 'vencido', en pas, mezones 'mesones', quinse, rrezidió, vazos 'vasos' «.

2.3.1. Sin pretender extraer conclusiones definitivas ni generalizadoras de la información histórica que antecede, lo cierto es que en ella se comprueba una confusión total de las grafías correspondientes a los fonemas medievales $/ s, z, \hat{s}, \hat{z} /$, con intenso predominio del uso de la $s$, hecho que denunciaría en 1577 el jerezano Juan de Baraona y de Padilla con estas palabras : "es comun defeto en el Andaluzia no saber pronunciar y escreuir como y quando se deue tres letras de las que nos siruen, las quales son C. s. Z., porque casi todos en general no se aprouechan de mas que de la $\mathrm{S}$. en quanto hablan y escriuen" «t.

Los materiales que en este trabajo se recogen no permiten establecer el mantenimiento de una oposición /s/ $\sim / z /$ entre sibilantes dorso-dentales sorda y sonora, respectivamente, derivadas la primera de /s, $\hat{s} /$ y la segunda de $/ z, \hat{z} /$, lo que no quiere decir que fuera desconocida en determinados grupos de hablantes andaluces esta doble realización fónica ${ }^{47}$. Pero todavía es más evidente para mí que ya antes del siglo xvi un seseo idéntico o muy similar al actual se hallaba ampliamente difundido en Andalucía, y no sólo entre usuarios de una norma de hablar estrictamente vulgar.

4 AHPS, Oficio 3. ${ }^{\circ}$, legajo 1.531 , fols. 782, 783, 784, 800 del cuadernillo $42 ; 803$, 804 del cuadernillo $43 ; 832$ del cuadernillo 44 .

45 AHPS, Oficio $15^{\circ}$, legajo 1.534 , primer folio suelto del ramo I, que se halla encuadernado.

46 Citado por Lawrence B. Kiddle, "Sibilant turmoil in middle Spanish (14501650)", Studies in Honor of Lloyd A. Kasten, Madison, 1975, pág. 333.

47 La pervivencia de este tipo de seseo en hablas judeoespañolas, aunque nunca habrá que perder de vista el acusado arcaísmo de las aljamas hebreas peninsulares, tal vez abone esta íltima suposición (cf. § 2.3.2.). Tampoco es posible descartar que durante la primera mitad del siglo xvi en Andalucía, en ciertos hablantes o en determinadas áreas, se mantuviera algún tipo de oposición entre las ant. $/ \hat{\mathbf{s}} / \mathrm{y} / \mathrm{z} /$, según defiende D. Catalán en "The end of the phoneme / $z$ / in Spanish", Word, XIII, 1957, págs. 282-322, artículo traducido al español y reeditado en Introducción plural a la Gramática Histórica, págs. 96-129. Pienso, sin embargo, que las conclusiones a las que este autor llega han de revisarse, en parte al menos, a la luz de la documentación que sobre el reajuste fonológico en cuestión se ha ido allegando desde que apareció su esestudio. Entre otras cosas, las mismas, o muy semejantes, reminiscencias medievales se darían en el fonetismo de otras regiones, salvo - y esto ni siquiera de manera totalmente excluyente- en lo que concierne a la confusión de $/ \mathrm{s} / \mathrm{y} / \mathrm{z} /$ con los primitivos $/ \hat{\mathbf{s}} /$ y $/ \hat{z} /$, respectivamente. 
2.3.2. Afirma M. Alvar que la desoclusivización de las dentoalveolares africadas es "fenómeno anterior a la conquista de Canarias y al descubrimiento de América", y es de la opinión de que en el nacimiento del seseo sefardita debió tener mucho que ver la norma de los judíos sevillanos, en contradicción de la tesis de A. Alonso que defiende la vigencia del fonema $/ \hat{\mathrm{s}} /$ en el momento de la expulsión ${ }^{18}$. Pero también asegura nuestro eminente investigador que "sin acabarse de consolidar el timbre seseante o ceceante del ceceo, el fenómeno pasó a Canarias y a América, donde se realizó como seseo", de tal modo que la nivelación seseosa, ya del todo cumplida en el último tercio del siglo XVI, estuvo en buena medida determinada por el influjo de los colonizadores no andaluces, que imprimieron esta precisa dirección al proceso porque el ciceo resultaba para ellos "demasiado estridente" $₫$.

Apenas puedo matizar tan sugestivo planteamiento en el sentido de que, a mi modo de ver, un seseo completo pudo ser asimismo trasplantado al Nuevo Mundo en el habla de muchos emigrados andaluces desde el comienzo de la colonización ${ }^{50}$. De hecho, si hemos de hacer algún caso a la interpretación de las grafías, este punto de vista se impone como una incuestionable realidad. Muchos otros datos podrían añadirse al corpus histórico que figura en parágrafos anteriores para probar mi aserto, pero me contentaré con recurrir a estas dos nuevas calas en fondos archivísticos sevillanos. La primera está verificada en un protocolo del año 1533 en el que no sólo se dan cacografías como conosco, Fernandes, Peres o Vazques con una ese, baja o alta, en lugar de $z$, sino que en el onomástico Rodrigues a su "ese sigma" final trazada en primer lugar se le ha superpuesto sobre la caja de escritura, $y$ por consiguiente en forma claramente visible, una $z$ de rectificación ortográfica $^{51}$. La segunda exploración probatoria se ha verificado en otros tex-

48 M. Alvar, A vueltas con el seseo y el ceceo, págs. 141-142. De todos modos, será preciso profundizar más en este aspecto histórico antes de aceptar el determinismo de lo sevillano en el seseo sefardí, porque en principio no parece que en la diáspora fuera muy acusado el peso demográfico de los judíos hispalenses, sobre todo después de la destrucción sufrida por la aljama de Sevilla en las revueltas de 1391.

1 Ibidem, págs. 138-139.

so Se trata, en cualquier caso, de una diferencia cronológica no muy acusada, pues el profesor Alvar afirmará también que "mal podían realizarse las tres etapas que Alonso señala para el cambio peninsular, porque a América va una lengua que ha alcanzado -ya- la tercera" (ibidem, pág. 139). Mi pensamiento es distinto en el sentido de que sostengo que en los inicios mismos de la colonización de las Indias entre los sevillanos que atravesaron el Atlántico había quienes usaban un seseo moderno plenamente cuajado, tal vez en número mucho mayor del que a primera vista pudiera sospecharse.

61 AHPS, Oficio $16^{\circ}$ (notaría de la calle de Tundidores), legajo 1.533, fols. 9r, $12 \mathrm{v}$ del primer cuadernillo; conosco tiene ese alta y se repite en los fols. $12 \mathrm{v}$ y $13 \mathrm{r}$. Otros ejemplos tengo de rectificaciones ortográficas semejantes a la que acabo de men- 
tos notariales, todos ellos firmados en 1560 por Juan de Santa María, que en el corto espacio de un folio facilitan estos 18 casos de faltas, algunas de ellas reiteradamente repetidas: avdensia 'audiencia', apelasión, conoser, contradesir, chansillerias, dependensias, desir, ynsidensias, ystansias 'instancias', juridisión, juridisiones, obligasiones, paresca, petisiones, presio, prouansas, Rodrigues, suplicasión ${ }^{52}$.

3. Hay una constante en el español escrito de la decimosexta centuria, y es que las confusiones grafémicas que en él se registran operan de manera muy distinta si quien escribe es andaluz o si tiene otra naturaleza regional. Efectivamente, en el primer caso - lo que no significa que ello se produzca ni sistemáticamente ni en todos los textos de procedencia meridional- las alteraciones ortográficas afectan a las cuatro sibilantes /s, z, s, $\hat{z} /$ entre sí, mientras que en el segundo supuesto la inestabilidad se limita a los elementos de cada par fonológico, /s, z/ y /s, $\hat{\mathrm{z}} /$, de modo independiente.

Vacilaciones gráficas que impliquen a los cuatro fonemas medievales mencionados, que aparezcan en textos no andaluces, únicamente ocurrirán cuando el redactor es bilingüe. En otra parte he señalado cómo el escribano de un documento aragonés del año 1506 comete toda suerte de equivocaciones con las grafías $s s, s, c$ y $z$, anomalías que se explican por la igualación seseosa de tipo catalán propia de su lengua materna ${ }^{58}$. Algo parecido sucede en cartas escritas el año 1580 por el verdugo de Murcia, pero originario de Valencia, Juan Batiste Blay, que también refleja el seseo catalán en formas como dezea 'desea', reseby 'recibí, syerto o syudat ${ }^{\text {54. }}$.

Volviendo al acervo documental aragonés, encuentro un protocolo zaragozano de 1581 escrito de su puño y letra por el fundidor Guillén de Tujarón (o Trujarón), que había llegado ya adulto a la capital del Ebro y que -salvo en los ejemplos azerqua, azer, Çaragosa, hiziendo 'haciendo', Lo-

cionar; por su número y por su significación histórica, esos hechos grafémicos merecen ser tratados en monografía aparte.

52 AHPS, Oficio $23 .^{\circ}$, legajo 1.560 , libro $2 .^{\circ}$, cuadernillo $2 .^{\circ}$, fol. 2r y v. En todas estas palabras, que con sus repeticiones sobrepasan los 50 registros, siempre se emplea la ese como signo de igualación fonética. Pueden descubrirse, claro está, ejemplos contrarios, lo que sucede en unos textos, también de 1560, firmados por Alonso de Laredo, donde junto a dies y sufisiente se encuentra bezó 'besó' (ibid., fols. 8 y 9 del libro segundo).

58 Juan A. Frago Gracia, "Nueva contribución a la historia del reajuste fonológico del español moderno", Cuadernos de Filología. Studia Linguistica Hispanica, II, 1980, págs. 59-60.

o4 Juan A. Frago Gracia, "El reajuste fonológico del español moderno en su preciso contexto histórico: sobre la evolución /š, ž / > /x/", Serta Philologica F. Lásaro Correter, Madrid, Ediciones Cátedra, 1983, I, pág. 227. 
renzo y ofrezca- emplea con toda regularidad la letra $s$ en dos docenas largas de formas tales como consertado, cosido, ensima, fiansa, sequia, siento, vesinos, etc. ${ }^{*}$. Del occidente peninsular puedo aducir el testimonio de un pequeño manuscrito extremeño del año 1601 editado por Rodríguez-Moñino, que refleja una lengua híbrida de español y portugués, carácter lingüístico que se traduce en grafías como pesa 'pieza' o matris, ésta con las variantes matrid y matriz ${ }^{56}$.

Fuera de tales situaciones, esos hechos ortográficos sólo muy esporádicamente tienen lugar en fuentes propiamente castellano-españolas no andaluzas. En las más de 200 páginas de protocolos aragoneses del siglo XVI ya citados no hallo más que estos pocos casos: algessenos 'aljeceños' (1599), çufrir (1581) y resibiendo (1582) ${ }^{67}$. Y en las Relaciones históricas toledanas que Sebastián de Horozco escribía hacia 1570 , no hay otra cosa que destacar que un repetido zuiza 'suiza' y el toponímico italiano Meçina 'Mesina' 68. Se trata, pues, de términos raros, nombres de lugar y extranjerismos, y de escasos apelativos españoles, algunos de ascendencia dialectal, en los que los trastrueques grafémicos ocasionales se han visto condicionados por los me-

* A. San Vicente, Monumentos diplomáticos sobre los edificios fundacionales de la Universidad de Zaragoza y sus constructores, Zaragoza, Institución Fernando el Católico, 1981, págs. 125-126. Este documento ha sido verificado por mí en el original guardado en el Archivo de Protocolos Notariales de Zaragoza, igual que todas las piezas de esta colección citadas a continuación. Desconozco, por otro lado, cuál sea el origen regional o nacional de este personaje, aunque, por otros rasgos lingüísticos en su escrito plasmados, barrunto que fuera de procedencia francesa.

- A. R. Rodríguez Moñino, Los tesoros escondidos. Pelos y señales para encontrarlos, según un curioso manuscrito de 1601, Badajoz, 1942, págs. 28, 30, 32. Abunda este texto en portuguesismos como apregoar, chombo, porta, termo, etc.

67 A. San Vicente, op. cit., págs. 127, 135, 290, refiriéndose la primera de estas citas al documento autógrafo del arquitecto vizcaíno Marco Mañaria. Aparte queda, claro está, el protocolo núm. 14, de seseo generalizado, que he traído a colación en la nota 55.

58 Sebastián de Horozco, Relaciones históricas toledanas. Introducción y transcripción de J. Weiner, Toledo, 1981, págs. 198, 199, 225 ; en el $D E C H$, s. v. suizo, se atestiguan variantes de este término con $s$ y $z$ en los siglos xv y XVI. Varios años después de escribir este estudio me veo en la obligación de introducir una cierta modificación en mi perspectiva histórica, en el sentido de que documentos leoneses y aragoneses del quinientos descubren más casos de grafías seseo-ceceosas de los que yo conocía, principalmente los debidos a autores nacidos en zonas arcaizantes todavía dialectales o con una acusada pervivencia de lo dialectal, en contraste con la cada vez más intensa marea castellanizante. Se trata de una cuestión lo suficientemente importante como para que sobre ella se establezca la correspondiente línea de investigación, y algo digo ya al respecto cuando me refiero al corpus técnico-científico escrito por un ingeniero de naturaleza seguramente oscense: Juan A. Frago Gracia y José A. García-Diego, Un autor aragonés para "Los veintiun libros de los ingenios y de las máquinas", Zaragoza, Diputación General de Aragón, 1988. 
canismos sociolingüísticos puestos en marcha por el proceso extraordinariamente complejo de la sustitución de un sistema fonológico por otro que es resultado de su misma transformación.

4. Muy antiguas dataciones tiene el seseo americano, y probablemente serían éstas anteriores si se despojaran fuentes de los primeros años del descubrimiento y colonización de América; de todos modos, a partir del año 1521 empiezan a abundar las noticias que sobre el particular incluye R. Lapesa en su Historia de la lengua española ${ }^{50}$. Por puras razones cronológicas, hay que pensar que quienes en las Indias redactaron textos con faltas reveladoras de confusión seseosa antes de 1550, año más año menos, debieron ser en su mayoría hombres nacidos en España, lo que es de todo punto incuestionable por referencia a los dos o tres decenios iniciales del siglo xvI.

Vistas así las cosas, el escribano de uno de tales corpus podía ser andaluz, o hispanohablante de otra procedencia, o, finalmente, individuo de naturaleza bilingüe, usuario del español y de otra lengua peninsular. La segunda circunstancia, en la que conforme avanza el tiempo es preciso contar también con la influencia de la sociedad criolla como decisivo factor de nivelación lingüística, se dará con mayor frecuencia cuanto más posibilidades haya de establecer largos períodos de convivencia entre hablantes adscritos a normas socioculturales y regionales diferentes, de lo que serían ejemplos señeros los casos del poeta Fernán González de Eslava (15.74), si hubiera sido realmente natural de Tierra de Campos, y del conquistador y cronista Bernal Díaz del Castillo (1568) ${ }^{\circ 0}$.

oo Madrid, Gredos, 1981, 9. ${ }^{\text {a }}$ ed., págs. 376-377, 568-569, y en El andaluz y el español de América, pág. 271.

60 R. Lapesa, Historia de la lengua española, pág. 568; El andaluz y el español de América, pág. 273. Recoge Lapesa en este punto los datos aportados por A. Alonso, si bien acaba descartando las noticias de confusión en Bernal Díaz, al descubrir que no era autógrafo el texto en cuestión, y añade el caso del guipuzcoano Francisco Ortiz de Vergara sacado a la luz por Claudia Parodi de Teresa (Para el conocimiento de la fonética castellana en la Nueva España...). Sin embargo, ni Parodi ni Lapesa caen en la cuenta de que el seseo de un vasco no tiene el mismo valor histórico que el de un hispanohablante monolingüe, pues en su bilingüismo subyace, y ocasionalmente actúa, el seseo de su lengua materna : a este respecto, será bueno recordar las igualaciones fonéticas reflejadas en documento zaragozano dado por un menestral vizcaíno (véase la nota 57), situación que se repetirá en escrito de su paisano Martín de Aranguren, amanuense de la carta indiana que más abajo manejo ( $\$$ 4.2.2., doc. VI). El peculiar fonetismo de los vascongados fue un factor más favorecedor de la expansión de la modalidad confundidora de las antiguas sibilantes en el español de América, siendo muy posible que de naturaleza idiomática vasca fuera también Fernán González de Eslava, a quien, en contra de lo que Alonso y Lapesa opinan, le atribuye origen navarro el redactor del correspondiente artículo de la Nueva Enciclopedia Larousse, Barcelona, Editorial Planeta, 1984, 2.a ed., t. V, pág. 4.463. 
4.1. Algún aspecto de lo que acabo de indicar puede rastrearse ya en el análisis que Claudia Parodi de Teresa hace sobre 14 breves manuscritos dados en la Nueva España el año 1523, pues significativos son, por ejemplo, los datos concernientes al vizcaíno Francisco de Orduña; pero más me importa ahora poner de relieve la postura que esta estudiosa adopta a propósito del andalucismo hispanoamericano: "La confirmación de estas teorías -dice- sólo se puede lograr por medio de estudios sistemáticos que reflejen la realidad lingüística americana desde sus orígenes" ${ }^{81}$. Porque no hay, ciertamente, más solución historiográfica sino la de acudir a una información de primera mano, que únicamente en los documentos se encuentra; esto, si no queremos movernos indefinidamente por caminos de controversia, a veces en demasía cargada de bizantinismo.

Hacen falta, pues, monografías como la de Olga Cock Hincapié, concretas y coherentes en la cronología y en la geografía de los textos manejados, aunque su elaboración sea siempre costosa y en ocasiones poco gratificante en cuanto a la brillantez de los hallazgos conseguidos. Por otro lado, no hay que olvidar que cada corpus tiene sus propias características, dependientes, en definitiva, de factores tales como la formación escolar, el espíritu de selección o el origen regional del redactor, aparte de otros más o menos accidentales.

T. Buesa se fija en los nombres de mujer Rudecinda y Capracia, con $c$ por $s$, y en un juego homonímico entre vaso y bazo, que figuran en El lazarillo de ciegos caminantes, impreso en Lima hacia 1775 y escrito por el asturiano Alonso Carrió de la Vandera, importante funcionario virreinal con largos años de permanencia en tierras americanas ${ }^{82}$. Pues bien, tan valiosos son estos registros documentales, salvadas las distancias meramente cronológicas, como el cúmulo de datos que contiene una pequeña composición burlesca de 1625, asimismo limeña, donde son casi generales grafías del tipo de ensima o narises ${ }^{68}$. Así se explica también que en informes judiciales de si-

\footnotetext{
61 Claudia Parodi de Teresa, Para el conocimiento de la fonética castellana en la Nueva España ..., págs. 115, 116.

62 T. Buesa Oliver, "Canarias en el Concolorcorvo", I Simposio Internacional de Lengua Española, Ediciones del Excmo. Cabildo Insular de Gran Canaria, 1981, página 329. De todos modos, es preciso tener en cuenta que nos hallamos ante una obra sumamente problemática en varios aspectos, como pone de relieve E. Carilla en El libro de los "misterios": "El lazarillo de ciegos caminantes", Madrid, Gredos, 1976. Algún ejemplo más de seseo señala Carilla en la pág. 84 de su libro.

88 Junto a las formas ensallarse 'ensayarse' y ahuyen 'aullen', testimonios de yeísmo: A. R. Rodríguez Moñino, "El Salpicón escolástico de Fr. Francisco de Oviedo (Vejamen universitario limeño de 1625)", Anuario de Letras, VII, 1968-1969, páginas 219-237.
} 
milares fechas e idéntico tribunal unas veces aparezca el seseo identificado en gran número de faltas ortográficas y otras de manera muy esporádica ${ }^{\text {*4 }}$, o que en los escritos del franciscano Juan de Silva, persona dotada de una gran cultura, sus más de veinte años de estancia en las Indias sólo se reflejen a través del léxico, pero no en el aspecto fonético ${ }^{65}$.

4.2. Ofrezco ahora el análisis de 40 documentos del Archivo General de Indias dados en su mayoría en la Nueva España y unos pocos en Cuba y La Española, pertenecientes a las Audiencias reales de Méjico y de Santo Domingo. Buen número de ellos está fechado a mediados del siglo XVI; otros, los menos, en el último tercio de esta centuria y primeros años de la siguiente.

\subsubsection{Textos en los que no se confunde $c-z \operatorname{con} s$ :}

Doc. I: "En este mes de jullio pasado me dieron vna letra de Vuestra Merced y con ella vna provisión ..."

Ciudad de Los Ángeles, 1551, postrero de julio.

Alonso de Buyça. Distinta letra en firma y texto

AGI, Audiencia de Méjico, Ramo Secular, legajo 168, cuadernillo 17, carta 3, fols. 5-6 ${ }^{\text {Br }}$.

64 Lucía García de Proodian, Los judios en América. Sus actividades en los virreinatos de Nueva Castilla y Nueva Granada. S. XVII, Madrid, 1966. El primer caso se da en la testificación inserta en las págs. 398-400; el segundo en la petición que recogen las págs. 306-308, con la excepción de un Conseción 'Concepción' y, tal vez, de un Suazo 'Zuazo'. Esta referencia bibliográfica la doy a título meramente informativo, pues corpus similares al que en ella se transcribe abundan en los archivos, y son las fuentes manuscritas las que más fiabilidad ofrecen en materia de fonética histórica.

6o P. Castañeda Delgado, Los memoriales del Padre Silva sobre la predicación pacifica y los repartimientos, Madrid, Instituto Gonzalo Fernández de Oviedo, 1983.

66 Por el contenido de su carta queda claro que este Alonso de Buiza es el identificado como natural de Villamartín (León), hijo del señor de esta villa y soldado imperial en Italia, que en 1528 fue con Pedro de Alvarado a Nueva España, donde más tarde ejercería de regidor $\mathrm{y}$ de corregidor: P. Boyd-Bowman, Indice geobiográfico de cuarenta mil pobladores españoles de América en el siglo XVI (1520-1539). t. II, México, 1968, núm. 6.016. La firma es de Alonso de Buiza, pero el texto, como arriba indico, es de diferente autor, y en casos idénticos a éste, frecuentísimos por otro lado en la documentación americana, no cabe hacer otra cosa que dejar constancia del puro y simple hecho lingüístico reflejado en el escrito en cuestión, acompañado de su cronología y de su correspondiente marco geográfico indiano, pero no son posibles otras consideraciones sociológicas.

67 Los restantes documentos de este legajo del Archivo General de Indias se referirán a "Méjico 168 ", signatura suya. 
Doc. II: "Como mi deseo y trabajo deva siempre ser fundado en el seruiçio de Dios nuestro señor ..."

Méjico, 1551.

Doctor Melgarejo. Autógrafo, igual que los docs. III, IV, V, VI ${ }^{68}$.

AGI, Méjico 168, cuadernillo 18, carta 1, fols. 1-2.

La grafía $s \zeta$ es $z \zeta$ en verbos incoativos como fauorezçer o parezçer hasta una docena de veces; este uso, que no constituye indicación clara de ceceoseseo, es regular con la excepción de un obedesçer repetido ${ }^{6 \theta}$.

Doc. III: “Dos cosas, assi por lo que soy obligado como por su illustríssimo Visorey don Luys de Velasco me lo aver mandado ..."

Méjico, 1552, 3 de enero.

68 Se trata de Bartolomé Melgarejo, catedrático de Decreto en la recién fundada Universidad de Méjico y procurador general de indios, amén de traductor de los clásicos latinos: María J. Sarabia Viejo, Don Luis de Velasco, virrey de Nueva España (1550-1564), Sevilla, Escuela de Estudios Hispanoamericanos, 1978, págs. 209, 217. Este doctor Melgarejo era natural de la localidad sevillana de Alanís y pasó a Méjico en 1539: Juan N. Vargas Vega, S. I., Andaluces en el descubrimiento de América y Filipinas, Sevilla, 1986, pág. 179.

69 Con todo, en su segundo texto (doc. III) se encuentra un paresca 'parezca', con la ese de trazado moderno, susceptible de tomarse por representación del modismo seseoso, aunque la indicación fonética sería más evidente si la grafía se diera en formas nominales o en verbos no incoativos. En cuanto al doblete grafémico paresçer-parezçer, es preciso tener en cuenta que tanto $s_{\xi}$ como $z \xi$ son signos gráficos de un único fonema, bien del ant. / $\hat{\mathrm{s}} /$, bien del que le sucede en el reajuste del español moderno.

Pero, aun concediendo que el seseo no se ofrezca con absoluta claridad en este autor, hay que considerar en primer lugar que son muy breves los escritos que de él analizo, $y$, en segundo lugar, que era un hombre dotado de cultura humanística bastante acendrada, la cual le permitía mantenerse fiel a una ortografía etimologizante y tradicional en lo tocante a las distinciones $b-v, x-g, j, c-z$ y $s s-s$, sólo rotas por algún ejemplo de alternancias, como el de impossible-posible del ya citado doc. III. Y todavía se descubren atisbos de su meridionalismo fonético en ciertos rasgos, menos exclusivos unos que otros, que parecen haber quedado plasmados en dichos corpus: a) todos ellos manifiestan una absoluta regularidad en el empleo de $h$ donde hubo /f / latina, muestra suficientemente evidente de que el escribano aspiraba; $b$ ) en el doc. IV se advierte la probable corrección de un he podido sobre un anterior he podio, y el sintagma "la dichas responsiuas cartas" (escrito junto ladichas) se encuentra enmendado mediante una ese luego añadida en superposición a la $a$ del artículo; $c$ ) y el doc. VI proporciona también otro ejemplo de $-s$ final de palabra corregida, suprimida más bien, aprovechando su trazo para la $a$ mayúscula inicial del vocablo siguiente: "por aver seruido en ellos avré de quedar por esclauo" (ello.Avré), sin olvidar un necessidar 'necesidad', con cambio de $-d$ por $-r$ bien conocido en la documentación andaluza de la época; $d$ ) menor seguridad hay en la interpretación del riga 'rija' con que Melgarejo termina todos sus memoriales, en el sentido de que pudiera indicar una pronunciación relajada del fonema $/ x /$, y no lo habría traído a colación si no fuera por el cuidado que en los demás casos el escribano pone para diferenciar $g$ de $j$, de acuerdo con la costumbre ortográfica más establecida. 
Doctor Melgarejo.

AGI, Méjico 168, cuadernillo 18, carta 11, fols. 22-23.

Con un parezçieron, parezçería.

Doc. IV: "Por quatro vezes que he escrito a V. M. açerca de los indios tenidos por esclauos que han proclamado y conseguido libertad".

Méjico, 1554, octubre.

Doctor Melgarejo.

AGI, Méjico 168, cuadernillo 19, carta 2, fols. 3-4.

Fauorezçer.

Doc. V: "Por otras de onze de abril del año passado de mill y quinientos y cinquenta y siete escriví de los indios..."

Méjico, 1558, 4 de enero.

Doctor Melgarejo.

AGI, Méjico 168, cuadernillo 15, carta 3, fols. 6-7.

Doc. VI: "Por otra de enero deste presente año escriví a Vuestra Alteza aver sido hasta el dicho día ..."

Méjico, 1558, 15 de junio.

Doctor Melgarejo.

AGI, Méjico 168, cuadernillo 15, carta 7, fols. 20-21.

Parezçe. También registro la forma necessidar 'necesidad', y la grafía riga 'rija', que aparece constantemente en la frase formularia final de los escritos del doctor Melgarejo.

Doc. VII: "A treynta de abril passado deste año de quinientos e çinquenta e vno escriuimos a Vuestra Magestad ..."

Méjico, 1551, julio.

Gonzalo de Aranda. Autógrafo ${ }^{70}$.

AGI, Méjico 168, cuadernillo 18, carta 5, fols. 9-10.

Doc. VIII: "En veinte y seis de mayo deste presente año me dio vuestro yllustre Viso Rey don Lujs de Velasco ..."

Méjico, 1551, 28 de mayo.

70 Este Gonzalo de Aranda actuó como contador especial de la Real Hacienda en Nueva España, adonde llegó con el visitador Tello de Sandoval, comisionado para la revisión de las cuentas atrasadas, si bien se ocuparía únicamente de las del tesorero Juan Alonso de Sosa (1531-1533): Antonio F. García-Abásolo, Martín Enríques y la reforma de 1568 en Nueva España, Sevilla, Publicaciones de la Excma. Diputación Provincial, 1983, pág. 192. Muy probablemente es el mismo Gonzalo de Aranda, de la burgalesa Aranda de Duero, que en 1528 fue a Santa Marta con el gobernador García de Lerma: P. Boyd-Bowman, Indice geobiográfico ..., II, núm. 2.224. 
Diego Ramírez. Autógrafo ${ }^{71}$.

AGI, Méjico 168, cuadernillo 18 , carta 4, fols. 7-8.

Doc. IX: "Entendiendo en los negoçios desta provinçia de Meztitlán, que por mandado de Su M. y de V. A. me fue mandado visitar ..."

Provincia de Metztitlán en Nueva España, 1554, 24 de enero.

Diego Ramírez. Autógrafo.

AGI, Méjico 168, cuadernillo 14, carta 8, fols. 23-24.

Doc. X: "En doze deste presente mes de hebrero rrescibí vna çédula rreal de V. Alteza dada en Monçón de Aragón ..."

Méjico, 1554, 14 de enero.

Diego Ramírez. La letra de la firma es distinta a la del texto, a su vez ambas idénticas a las de la firma y texto correspondientes a los documentos II, III, IV, V del § 4.2.2., y XI de este parágrafo.

AGI, Méjico 168, cuadernillo 14, carta 6, fols. 19-20.

Doc. XI: “En catorze de hebrero de este presente año dí rrelación a Vuestra Alteza ..."

Méjico, 1554, 23 de marzo.

Diego Ramírez. Texto y firma con letra diferente.

AGI, Méjico 168, cuadernillo 14, carta 5, fols. 17-18.

Doc. XII: "De La Palma avisé de lo hasta allí a los pilotos ..."

Laguna de ..., 1552, enero. El capitán Salaçar, del puerto de Santos a XX de junyo de 1553.

El capitán Juan de Salazar. Autógrafo ${ }^{72}$.

AGI, Méjico 168, cuaderno 18, carta 10, fols. 19-21.

71 Diego Ramírez había nacido en Soria ; casado hacia 1528, viajó a Nueva España alrededor de 1534 con cédula real "para ser proveído", siendo vecino de la ciudad de Méjico por 1547, a la sazón con cuatro hijos, dos varones y dos hembras: P. BoydBowman, Indice geobiográfico ..., II, núm. 10.575. Este Ramírez fue visitador duramente combatido por los encomenderos y, muerto en 1555, dejó en pésima situación económica a su viuda y a sus cuatro hijos, uno de los cuales será autor del doc. XVIII de este mismo apartado. Para más datos biográficos, véase María J. Sarabia Viejo, Don Luis de Velasco ..., págs. 18, 370, 372, 382-383.

72 Como Ruy Díaz de Guzmán recuerda, de "los que traía de más cuenta" la armada del Adelantado don Pedro de Mendoza uno era "el capitán Salazar de Espinosa de la Villa de Pomar": La Argentina, ed. de Enrique de Gandía, Madrid, Historia 16, 1986, págs. 110-111. Según indica Gandía, nació en Espinosa de los Monteros, cerca de Pomar, este burgalés que incluso en el escrito suyo al que ahora hago referencia se ufana de haber sido fundador del fuerte de Asunción del Paraguay. Ignoro el motivo por el cual un texto perteneciente al área del Río de la Plata se encuentra inserto en un legajo mejicano; quizá ha mediado en ello la distracción de un archivero o el descuido de alguno de los investigadores que han trabajado en el Archivo General de Indias. 
Doc. XIII: "Yo partí de Sanlúcar de Barrameda el año de cinquenta por mandado de V. Alteza y de su Consejo rreal de Yndias ..."

Puerto de Santos y San Vicente, 1553, 5 de junio.

El capitán Juan de Salazar. Distinta letra en la firma y en el texto. AGI, Méjico 168, cuadernillo 14, carta 2, fols. 3-5.

Doc. XIV: "Por mandado de don Luys de Velasco, vuestro Visorrey desta Nueua España, despaché en diez de enero deste presente año ..."

Veracruz, 1553, 12 de mayo.

García de Escalante Alvarado. Autógrafo ${ }^{73}$.

AGI, Méjico 168, cuadernillo 14, carta 1, fols. 1-2.

Doc. XV: “En la flota que salió por el mes de abril de este año..."

Ciudad de los Ángeles, 1554, 30 de octubre.

Pedro Ladrón de Guevara. Autógrafo.

AGI, Méjico 168, cuadernillo 19, carta 10, fols. 21-22.

El redactor sólo confunde $s s-s$ y $c-z$, como sucede en la mayor parte de las cartas de este parágrafo, y él mismo indica su procedencia regional: "Soy natural de la villa de Madrid, hijo de don Ladrón de Guevara y de doña Francisca de Toledo, criados de V. Alteza y de su real casa. A que pasé a poblar este Reyno de Vuestra Alteza con mj muger y hijos deciséys años. Truje cédulas reales de su S. C. C. R. M."

Doc. XVI: "El padre fray Pedro de la Peña, prior de Sancto Domingo en esta cibdad de México ..."

Méjico, 1554, 2 de febrero.

Juan Negrete. Autógrafo ${ }^{7 *}$.

78 García de Escalante Alvarado en 1554 mandaba la flotilla que acudía a rescatar a otra naufragada en la costa de Florida, y más tarde sería director de las obras de San Juan de Ulúa: María J. Sarabia Viejo, Don Luis de Velasco ..., págs. 114, 452. No es otro personaje que el García de Alvarado, hijo del licenciado Escalante y de doña Beatriz Osorio, vecino de la cántabra Ampuero, pasado a las Indias en 1538 con la armada de Pedro de Alvarado: Archivo General de Indias, Catálogo de pasajeros a Indias durante los siglos XVI, XVII y XVIII, Sevilla, 1942, t. II, núm. 5.201; P. Boyd-Bowman, Indice geobiográfico ..., II, núm. 7.676. Edito este texto en "Una introducción filológica a la documentación del Archivo General de Indias", Anuario de Lingüística Hispánica, III, 1987, págs. 93-94. El firmante alega en él "los serviçios de mi padre" para lograr el nombramiento real que solicita, y dado que era éste un argumento usualmente argüido por los hijos de los primeros conquistadores, me queda la duda de si nuestro personaje no había ido a América para reunirse con su progenitor, o para recoger los frutos de su fama, como sospechaba en el citado artículo, acertando en él con la región de origen, si bien no con la localidad de procedencia del autor del corpus que ahora considero (pág. 83, n. 28).

74 De la lectura del memorial se desprende que lo escribió el arcediano del mismo 
AGI, Méjico 168, cuadernillo 14, carta 7, fols. 21-22.

Doc. XVII: "Veso las rreales manos de V. M., y como V. M. me mandó benjr estas partes a que lo siruiese ..."

Méjico, 1558, 26 de septiembre.

Gregorio de Pesquera, sacerdote. Autógrafo ${ }^{75}$.

AGI, Méjico 168, cuadernillo 15, carta 8, fols. 22-23.

Doc. XVIII: "La yntolerable pobreza que consegujmos la muger e hijos de Diego Ramjrez, difunto, a qujen Vuestra Magestad cometjó la vjsita desta tierra ..."

Méjico, 1558, 4 de enero.

Diego Ramírez de Barrionuevo. Autógrafo ${ }^{78}$.

AGI, Méjico 168, cuadernillo 15, carta 1, fols. 1-3.

Doc. XIX: "Yo he cunplido lo que por ese real Consejo me fue mandado que viniese a rresidir al puerto de San Juan de Lúa ..."

San Juan de Ulúa, 1558, 13 de julio.

Doctor Pedro de Santander. Distinta letra en la firma y en el texto.

AGI, Méjico 168, cuadernillo 15, carta 6, fols. 17-19.

Por $s s-s$ sólo se emplea el signo simple.

nombre que en 1554 era rector de la Universidad de Méjico: María J. Sarabia Viejo, Don Luis de Velasco ..., págs. 132, 210.

75 Gregorio de Pesquera, de quien desconozco su naturaleza regional, fue protector del colegio de mestizos de San Juan de Letrán: María J. Sarabia Viejo, Don Luis de Velasco ..., pág. 196. En su carta, donde menciona algún aspecto de su reciente viaje a España, este clérigo confunde a veces $c$ con $z$, únicamente emplea la letra $s$ y nunca ss, hasta en los imperfectos de subjuntivo, y sobre la $-o$ final de deseoso coloca la -s de plural que había olvidado: "siempre tubieron por el camjno y por la mar hasta llegar a esta cibdad grandes contiendas y discusiones y pasiones entre sy, y gran apetito y deseo de mandar, y deseosode [con $s$ superpuesta] ynteresar hazienda para sy...". Pero no dispongo de un punto de comparación para ir más allá del mero lapsus cálami.

78 Es hijo del visitador soriano autor de los docs. VIII y IX, autógrafos también, de este apartado. Teniendo en cuenta el corto espacio de tiempo que media entre el casamiento de sus padres y el viaje de éstos a las Indias, es de suponer que Ramírez de Barrionuevo partiera de España siendo muy niño, si no es que vio la luz por primera vez en tierras mejicanas. Comoquiera que sea, la adquisición del lenguaje la llevó a cabo al otro lado del Atlántico, y en su escrito no se aprecian confusiones entre $s$ y $c-z$. Tal vez pudo más en él su entorno familiar que el medio social, en el que, por otro lado, coexiste la distinción junto a la norma confundidora. Sería oportuno, de todos modos, analizar más textos de este escribano, seguramente identificable con el Diego Ramírez que en 1579-1580 actuaba como contador de la Hacienda Real en Nueva España, lo que significaría que había recibido de la Corona la satisfacción que en nuestra carta pedía por los servicios que su progenitor había prestado: Antonio F. García-Abásolo, Martín Enríquez y la reforma de 1.568 on Nucva España, pág. 260. 
Doc. XX: "Porque la flota de Antonio de Aguayo e Pedro las Roelas y en otras tres naos que an partido ..."

Méjico, 1559, 15 de octubre.

Doctor Pedro de Santander. No coincide la letra de la firma con la del texto, a su vez diferente al documento anterior, de otro redactor.

AGI, Méjico 168, cuadernillo 15, carta 9, fols. 24-25.

Doc. XXI: “Don Luis de Velasco, Vissorrey por V. Magestad en esta Nueua España, murió postrero de julio ..."

Méjico, 1564, septiembre.

Firma, con distinta letra a la del texto, el hijo del fallecido.

AGI, Méjico 168, cuadernillo 19, carta 9, fols. 19-20.

Doc. XXII: “En la gran çibdad de Tenuxtitán, México de la Nueba España, veynte e ocho días ..."

Méjico, 1545, 28 de enero.

Juan Muñoz sacó el traslado ${ }^{77}$.

AGI, Audiencia de Méjico, Ramo Secular, legajo 96, carta 8, fols. 27$33^{78}$.

Doc. XXIII: "Por el mes de agosto del año de quarenta y seys, dendel monesterio de Santo Domyngo de Lima ..."

Méjico, 1547, 15 de abril.

Alonso de Montemayor firma. Otra letra en el texto.

AGI, Méjico 96, carta 1, fols. 1-2.

Doc. XXIV: "Como yo sea criado e humill vasallo de V. M. y mi zelo sea de mirar y procurar el seruicio de Dios y el de V. M. ..."

Méjico, 1554, 7 de noviembre.

Antonio de Aguayo. Autógrafo ${ }^{\text {}}$.

AGI, Méjico 168, cuadernillo 19, carta 4, fols. 8-10.

77 No tengo datos mínimamente seguros de cuál fuera el sitio donde nació este amanuense, cuyo nombre se repite hasta la saciedad en los catálogos de pasajeros a Indias.

78 Como pertenecientes a "Méjico 96" se citarán los demás documentos de este legajo.

$7 \theta$ Antonio de Aguayo, natural de Portillo (Valladolid) e hidalgo, viajó a Cuba hacia 1525 y dos años después estaba en Florida con Pánfilo de Narváez, participando luego en la conquista de Nueva Galicia junto a Nuño de Guzmán, territorio que pacificaría en 1541; fue encomendero además de hombre de armas: P. Boyd-Bowman, Indice geobiográfico..., II, núm. 11.946. Llevaba ya casi treinta años en las Indias cuando escribe este memorial en el que denuncia ciertos desmanes cometidos mientras él era regidor de la Villa de la Purificación. 
Doc. XXV: "En la gran ciudad de México de la Nueva España, doze días del mes de marzo de mjl e quinientos e sesenta años ..."

Méjico, 1560.

Juan Caro. Autógrafo ${ }^{80}$.

AGI, Méjico 96, carta 12, fols. 63-83.

Doc. XXVI: "A pedimiento de los yndios del pueblo de Thenango, questá en la Corona rreal ..."

Méjico, hacia 1560.

Doctor Horozco. Autógrafo ${ }^{81}$.

AGI, Méjico 96, carta 12, fol. 82v.

Doc. XXVII: “Fray Juan de Córdova, de la Orden de Santo Domingo, en nombre de los yndios ..."

Méjico, 1560.

Fray Juan de Córdoba. Autógrafo ${ }^{82}$.

AGI, Méjico 96, carta 12, fol. 62.

Se trata del famoso dominico autor de la conocida obra Del Arte en lengua zapoteca (Méjico, 1578), a uno de cuyos pasajes recurrió A. Alonso para probar que en Toledo y en el Sur todavía a mediados del siglo xvi se mantenía la distinción $s s-s$ y $c-z^{83}$. Sin embargo, en esta página manuscrita no se registra otra grafía que $s$, y nunca ss: neçesidad, vasallos, hiziesen, pidiesen ${ }^{84}$

80 Hay un bachiller Juan Caro, de Martín Muñoz de las Posadas (Segovia), embarcado el 29 de noviembre de 1559 con destino a América para servir como relator de la Audiencia de Lima: Archivo General de Indias, Catálogo de pasajeros..., III, núm. 4.440. Aunque para que tal identificación sea posible debería haberse dado un cambio de destino de última hora o que se anotara indebidamente en dicho catálogo Audiencia de Lima por Audiencia de Méjico en relación con este Juan Caro, nombre por lo demás varias veces registrado entre los viajeros a Indias.

81 Veinticuatro personas con este apellido, de las cuales seis van a Méjico, se hallan en el t. II del Indice geobiográfico de Boyd-Bowman, pero a ninguna se le atribuye el grado de doctor.

82 Según Boyd-Bowman, fray Juan de Córdoba era originario de Toledo, hijo "de padres nobles", el cual, después de haber combatido en Europa, pasó a Méjico "recién conquistado" donde el año 1544 profesó en la Orden de Predicadores, de la que sería provincial en 1568: Indice geobiográfico ..., II, núm. 11.244.

83 A. Alonso, De la pronunciación medieval a la moderna en español, Madrid, Gredos, 1967, II, pág. 23. Alonso se hace eco de las dudas existentes sobre si Juan de Córdoba fue toledano o cordobés (op. cit., I, págs. 340-341).

84 Publico este texto en Una introducción filológica a la documentación del Archivo General de Indias, pág. 95. Acabo de descubrir otra carta del dominico indiano, del año 1548, en la que también usa únicamente la letra $s$ donde se ponía el signo simple o el doble ss, incluso en los imperfectos de subjuntivo: AGI, Méjico 96, ramo II, fol. $34 \mathrm{r}$ y $\mathrm{v}$. 
Doc. XXVIII: “El Bachiller Andrés de Valdés, cura de Sant Christóual de la Hauana y Guanauacoa ..."

Cuba, 1569, junio.

Bachiller Valdés. Autógrafo ${ }^{85}$.

AGI, Audiencia de Santo Domingo, legajo 153, carta 12 del ramo I, fols. $57-59$.

Distingue ortográficamente hasta $s s-s$.

Doc. XXIX: “Antonio Sánchez de Moya, canónigo nombrado de la santa yglesia de Sanctiajo de Cuba, digo que a mi notiçia ..."

Santiago de Cuba, 1613, 19 de junio.

Antonio Sánchez de Moya. Autógrafo ${ }^{86}$.

AGI, Audiencia de Santo Domingo, legajo 153, ramo IV, fols. 86v-87.

Nótese la grafía Sanctiajo por Santiago.

4.2.2. Textos en los que se confunde $c-z$ con $s$ :

Doc. I: "Los días passados escriuí a V. M. dando cuenta por mi carta y por una relaçión de todo lo sucedido en el Perú hasta allí ..."

Méjico, 1547, 21 de noviembre.

Alonso de Montemayor. Letra distinta en la firma y en el texto.

AGI, Méjico 96, carta 2, fols. 3-5.

En los tres folios de este texto, de letra menuda y muy elegante, sólo se cometen las confusiones conosco y prezeas 'preseas'.

Doc. II: "Por otras que e escripto a Vuestra Magestad e dado relaçión cómo en veynte y seys de mayo ..."

Méjico, 1551, 3 de agosto.

Diego Ramírez. La letra de la firma no coincide con la del texto, lo mismo que en los docs. III, IV y V.

AGI, Méjico 168, cuadernillo 18, carta 6, fols. 11-12.

Constantemente se distingue en la ortografía, salvo en un acresentamiento al final del documento.

Doc. III: "En diez y siete de agosto deste presente año dí rrelaçión a V. Alteza de lo tocante ..."

Méjico, 1553, 20 de noviembre.

Diego Ramírez. No es autógrafo.

85 Ignoro su naturaleza regional.

86 De procedencia geográfica desconocida para mí. Su memorial de descargo lo edito en Una introducción filológica a la documentación del Archivo General de Indias, pág. 97. 
AGI, Méjico 168, cuadernillo 14, carta 3, fols. 6-14.

Encuentro las cacografías acresentado, Belásquez, desasoçiego, en dos ocasiones, eçesiba en cinco casos, yntereçe 'interese, interés', con dos ejemplos, jusgado, Mestitlán-Meztitlán, sesado.

Doc. IV: "En veynte de nobienbre del año próximo pasado de quinjentos y çinquenta y tres dí rrelaçión a V. M., ques la que conestava [sic] del estado en que ..."

Méjico, 1554, 19 de enero.

Diego Ramírez. La letra del redactor no coincide con la del firmante.

AGI, Méjico 168, cuadernillo 19, carta 6, fols. 13-14.

Presenta la confusión çufría. El texto es igual al siguiente, excepción hecha de algunos signos diacríticos y de las formas eçesos, suçedido, maíz en el V, en éste excesos, subçedido, mahiz.

Doc. V: "En veynte de nobienbre del año próximo pasado de quinjentos e cinquenta e tres..."

Carta copia de la anterior.

AGI, Méjico 168, cuadernillo 19, carta 7, fols. 15-16.

Tres veces ȩ̧esos.

Doc. VI: “Teniendo V. Magestad relaçión verdadera así por carta de fray Juan de Çumárraga, ques en gloria ..."

Méjico, 1551, 7 de agosto.

Martín de Aranguren. Autógrafo ${ }^{87}$.

Sólo al final se halla un sesárea 'cesárea', en expresión formularia.

AGI, Méjico 168, cuadernillo 18, carta 7, fols. 13-14.

Doc. VII: "Por hebrero deste año de çinquenta y quatro escreuj a V. Magestad suplicando ..."

Méjico, 1554.

Juan de Ojeda. No es autógrafo el texto, de bellísima factura.

AGI, Méjico 168, cuadernillo 19, carta 8, fols. 17-18.

Cacografía esesivos.

87 Martín de Aranguren fue vecino de Lequeitio (Vizcaya), hijo de Ochoa Ruiz de Aranguren y de Marina de Amaya, y pasó a Méjico en 1538: P. Boyd-Bowman, Indice geobiográfico ..., II, núm. 12.421. El seseo que Aranguren manifiesta en su escritura, ¿lo adquiere en Nueva España, durante los trece años de estancia previos al momento en que redacta el texto que analizo, o resulta de su materna lengua vasca? Pienso que más bien se trata de lo segundo, aunque inevitable era una cierta confluencia de su modismo patrimonial con el fonetismo confundidor arraigado por entonces en un importante sector de la sociedad indiana que lo acoge. 
Doc. VIII: "Como sea criado e humil vassallo de V. M. y mi zelo sea de mirar y procurar el seruicio de Dios ..."

Méjico, 1554, 25 de octubre.

Antonio de Aguayo. Es dudoso que se trate de un autógrafo.

AGI, Méjico 168, cuadernillo 19, carta 3, fols. 5-7.

Aquí la falta de ortografía es un ynterseción 'intercesión'.

Doc. IX: "Tres cosas han puesto silençio a mi pluma días ha para no aver hefetuado lo que agora por ésta, la primera, la poca notiçia ..."

Méjico, 1558, enero.

Sebastián Vázquez. Autógrafo ${ }^{88}$.

AGI, Méjico 168, cuadernillo 15, carta 4, fols. 8-11.

Desliza un perjuizio, intercambia continuamente $s s$ y $s$, y pone un $d i$ sençiones 'disensiones'.

He aquí lo que este colonizador nos dice sobre su origen: "Yo me llamo Sebastián Vázquez [...] y por su real merced fui mucho tiempo reçeptor en su Abdiençia que reside esta çibdad de México. Soy natural de la çibdad de Granada, aunque mis padres no lo fueron de allí, sino del Reyno de Castilla la Vieja [...]. Aunque su Merced no.me conosçe ni creo de mí terná notiçia, así por el mucho tiempo que ha que pasé a estas partes, como por aver yo nasçido y criádome en Granada y su Merçed no. Residí en aquella real Abdiençia en el oficio del Secretario Diego Gómez de Gumiel diez años. Ha ueynte que pasé a esta Nueba España; ha diez y siete que me casé en esta çibdad con hija de Francisco de Terrazas, uno de los primeros conquistadores de esta Nueua España que a ella pasaron con el Marqués" (líneas 27-42).

Doc. X: "Los días pasados por carta de V. M. vino a esta ciudad vn frai Christóval de Luna con vna patente de nuestro General y maestro ..." Santo Domingo, 1577, 15 de junio.

Fray Diego de Carvajal, prior. Autógrafo ${ }^{80}$.

AGI, Audiencia de Santo Domingo, Cartas y expedientes de personas eclesiásticas, legajo 96, ramo I, fols. 17-18.

En apenas folio y medio se cometen los errores ortográficos fiansas, nes-

88 Como escribano de la Audiencia de Méjico trabajó el granadino Sebastián Vázquez: María J. Sarabia Viejo, Don Luis de Velasco ..., págs. 23, 291.

so De este personaje y de la edición de su texto me ocupo en Una introducción filológica a la documentación del Archivo General de Indias, págs. 88 y 95-96: me inclinaba allí por el origen andaluz de fray Diego de Carvajal, y un religioso de igual nombre formaba parte del grupo de agustinos que con fray Pedro de Cepeda partía hacia el Perú en diciembre de 1557: Archivo General de Indias, Catálogo de pasajeros ..., III, núm. 3.866 . 
çecidades, rresçide 'reside', zasón 'sazón', además de juiendo 'huyendo', generar 'general' y "saque de las casa reales".

Doc. XI: "Mi gobernador y cappitán general de la ysla de Cuba: Por parte de Juan de Góngora, presbítero ..."

Santiago de Cuba, 1609, 14 de junio.

Gabriel de Santisteban es el escribano que hace el informe ${ }^{80}$.

AGI, Audiencia de Santo Domingo 153, ramo IV, fols. 81-86.

La importancia de este documento para la historia del español de América es extraordinaria, pues el seseo aparece generalizado en sus seis folios con más de un centenar de errores, en los que predomina el empleo de la $s$ (acresentar, desente, forsosso, nesesario, nesesidad, parescr, resiuido, saserdote, sédula, etc.), aunque también hay casos de ss por c-z (mosso, en tres ocasiones), de $z$ por $s$ (bezó), y de $c$ por $s$ (çacristía, ynquiciçión, conçideraçión, ygleçia, nesecidades, requicitos). Pero hay más, pues tres veces se registra el uso de $h$ por $g$ (las tres con el adv. rrecohidamente) y una el de $j$ por $h$ ("se me a jecho"), prueba segura de la vigencia del moderno fonema $\operatorname{velar} / \mathrm{x} /$ en el español común de la época e indicio bastante seguro de su pronunciación aspirada en el área del Caribe. $\mathrm{Y}$ todavía habría que resaltar en este texto las atestiguaciones otlas 'otras' y rública 'rúbrica'.

4.3. De los 40 documentos transcritos, en principio -luego matizaré esta clasificación inicial- 29 no presentan confusiones de $c$ - $z$ con $s$ frente a los 11 restantes, lo cual no significa, sin embargo, que en el español americano de ese período histórico predominara la distinción sobre el seseo, porque en ningún momento se me ha ocurrido hacer una selección documental con pretensiones ni estadísticas ni de geografía lingüística. Dicho esto, habrá que pensar en la naturaleza regional del redactor de cada uno de ellos, lo que, por desgracia, no siempre es fácil de averiguar. Se confiesa madrileño el autor de uno de los que distinguen (doc. XV) ${ }^{\bullet 1}$, Pedro Ladrón de Guevara, y granadino el de otro de los que confunden (doc. IX), Sebastián Vázquez, y en este punto el factor sociocultural irremediablemente entra en juego. En efecto, el mencionado emigrado andaluz era hijo de castellanos viejos, habiendo él nacido en Granada a finales del siglo xv o muy a comienzos del xvi, de manera que el disençiones de su escrito plantea la siguiente pregunta: ¿asimiló dicho hablante la correspondiente modalidad fonética en su infancia y juventud, transcurridas en la Andalucía oriental re-

- De procedencia desconocida.

o1 En lo sucesivo habrá de entenderse que el documento distinguidor mencionado tiene sus referencias archivísticas y lingüísticas en $\S$ 4.2.1., mientras que las correspondientes a los textos confundidores se hallan en $\S$ 4.2.2. 
cién reconquistada, o durante sus veinte años de permanencia en América? No tengo datos para contestar a esta interrogación, aunque desde luego se puede afirmar que parecido sería el valor histórico de cualquiera de las dos posibles soluciones de un problema que tiene en su base el común denominador del contraste o contacto de normas diferentes como factor desencadenante del proceso en cuestión, de localización andaluza en el primer caso $y$ americana en el segundo.

4.3.1. Ahora bien, habida cuenta de que el fonetismo de la lengua materna se adquiere en los más tiernos años de la vida del hombre, preferiría aceptar la hipótesis inicial, porque la experiencia enseña que entre los adultos distinguidores de $/ \theta / \mathrm{y} / \mathrm{s} /$ que hoy pasan a la América española o se trasladan a Andalucía son muy pocos los que llegan a sesear o cecear y muchos más los que experimentan determinados relajamientos consonánticos, así en $/-\mathrm{s} /$ o en $/ \mathrm{x} /$. Bien es verdad que en un estadio articulatorio intermedio entre $/ \hat{\mathbf{s}}, \hat{\mathrm{z}} / \mathrm{y} / \boldsymbol{\theta} /$ la situación tal vez variaría notablemente al respecto $\mathrm{y}$ sobre ello habría que reflexionar con mayor detenimiento, pero por regla general debe pensarse que el español indiano que en sus escritos desliza errores denotadores de seseo está descubriendo un modismo antes enraizado en su lugar de procedencia, por más señas andaluz para la mayoría de los casos. Es, seguramente, lo que ocurrió con nuestro Sebastián Vázquez, que su seseo o ceceo lo llevara ya consigo cuando desde la Península partió hacia las Indias, y lo propio hubo de suceder con otros anónimos escribanos de documentos confundidores firmados de su puño y letra por personajes más conocidos. Por lo demás, y para mayor complicación, toda precaución es poca en el resbaladizo terreno de la identificación paleográfica, especialmente en un siglo como el xvi en el que los muchachos aprendian a escribir con los mismos modelos de cartillas caligráficas, y, así, yo sólo he apuntado el carácter autógrafo de un texto cuando no mediaba el menor resquicio para la duda, de tal modo que, por ejemplo, he señalado mi reticencia a concederle al vallisoletano Antonio de Aguayo la autoria del doc. VIII, no sólo porque no viera una igualdad tan absoluta entre la letra de la firma y la del texto como la verificada en otro corpus suyo del anterior apartado documental, sino también por el seseoso ynterseción 'intercesión' que en él se encuentra, sin que ninguna forma similar contenga el incuestionable ológrafo ${ }^{82}$.

82 Véase lo dicho de Antonio de Aguayo en la nota 79. E1 documento donde no se confunde $s$ con $c-z$ es posterior al otro, que le sirve de modelo a Aguayo, aun introduciendo de su parte variaciones ortográficas, pues, verbigracia, ya en el mismo encabezamiento de la carta el escribano confundidor puso vassallo, mientras que por vasallo se inclina el castellano viejo en la segunda misiva que dirige al Rey, seguramente para insistir en la resolución favorable a su petición. 
Mucho es necesario precaverse ante conflictos de interpretación como el que acabo de exponer, porque, insisto en ello, si bien no es impensable que la contaminación seseo-ceceosa al cabo del tiempo se produjera dentro de la nueva realidad americana en el hablar de algunos de los que habían salido de España sujetos a distinta norma fonética, lo más lógico y probable es que el hecho se diera entre sus descendientes criollos, y aun así no con total determinación, según lo que parece desprenderse del doc. XVIII de Diego Ramírez de Barrionuevo, hijo de padres sorianos ${ }^{93}$. De idéntica ascendencia provincial que Antonio de Aguayo era Bernal Díaz del Castillo, de quien $R$. Lapesa ha acabado por rechazar su confusión seseosa al descubrir que no era autógrafo el manuscrito de su Verdadera historia (cf. n. 60). Más aún, en los 299 folios de que consta el códice "Guatemala" de esta crónica intervino al menos media docena de copistas, algunos de ellos excelentes calígrafos, de los cuales folios a Díaz del Castillo se le podrían atribuir alrededor de 10, y aun así con criterios más bien "impresionistas" ${ }^{04}$.

4.3.2. Al hilo de la cuestión cuantitativa significaré que varios documentos del primer apartado -en concreto los núms. II, III, IV, V, VIperfectamente podrían encuadrarse con los del grupo segundo. Al menos por lo que a su andalucismo fonético concierne, la clasificación alternativa que propongo tendría plena justificación a tenor de ciertos rasgos lingüísti$\cos$ ya comentados ${ }^{95}$, y, si se me apura, también el paresca 'parezca' del doc. III de Melgarejo - forma que, por cierto, he atestiguado en otros textos suyos no citados aquí- resultaría suficiente para colocarlo bajo el marbete del seseo. Si no he hecho hincapié sobre el particular es porque no deseo perder el tiempo más adelante con quienes se muestran reacios a abdicar de posturas historicistas divergentes de la mía - aparte de que lo mismo negarían validez a 20 ejemplos más de paresca-; por esto y porque nada me costaría ahora acopiar documentos indianos con alternancias de $s$ y $c-z$.

93 Confróntese lo referido en la nota 76 , e indico que no desistiré de seguir la pista fonética de este funcionario indiano en otros escritos suyos conservados en el Archivo General de Indias.

o4 Me facilita estos datos el Dr. D. José A. Barbón Rodríguez, con quien he coincidido en la sevillana Escuela de Estudios Hispanoamericanos, cuya edición crítica de la Historia verdadera de la conquista de la Nueva España va a ser publicada en breve por el Instituto de Cooperación Iberoamericana. Según me comunica el mismo investigador, en una de las cartas atribuidas a Bernal Díaz - no es seguro que le pertenezca como escrito autógrafo, aunque, según él, hay muchas posibilidades de que ello sea así-, se encuentran un conosco y un beses, concretamente en la que dirige al Emperador el 22 de febrero de 1552, es decir, casi cuarenta años después de la llegada del cronista a las Indias. Confío en poder analizar pronto una reproducción del original de este texto que gentilmente va a poner a mi disposición el citado americanista.

95 Véase lo referido en la nota 69. 
De los escritos de Melgarejo me interesa destacar más que el probable seseo que algunos de ellos revelan, lo que suponen de diacrónica piedra de toque para los datos que la geografía lingüística actual arroja, pues, efectivamente, Alanís, cuna suya y localidad actualmente seseosa, debía serlo ya en la primera mitad del quinientos, probándose en tal supuesto la multisecular estabilidad de las isoglosas fonéticas en esta zona del dominio andaluz. $\mathrm{Y}$ muy singularmente habría que resaltar un decisivo aspecto sociolingüístico, quizá apenas aceptable para los que poco menos piden que auténticas transcripciones fonéticas en textos del pasado - la verdad es que ello suele ocurrir a estudiosos bastante desafectos de los archivos-, prurito que llevado a sus últimas consecuencias resulta esterilizante y falaz. Pero no me detendré en la defensa de un método que estimo insustituible, del todo razonable y que muchísimos hispanistas han asumido plenamente.

Opino que si un humanista como el doctor Melgarejo cae en faltas como las que he puesto de relieve, a pesar de su elevadísima formación escolar y del exquisito espíritu de corrección que en sus escritos late, esos errores, por escasos que sean, para el historiador de la lengua encierran tantas o más claves que los abundosamente cometidos por amanuenses de nivel intelectual mucho menor. $\mathrm{Y}$, aunque el ejemplo propuesto es de todos los que de esta investigación puedo escoger el más llamativo, otros semejantes cabría aducir en los que tampoco habría grandes dificultades para establecer idénticos comentarios. Así el ya mencionado caso de un aislado disençiones 'disensiones' perteneciente al granadino Sebastián Vázquez es sumamente ilustrativo para el lingüista, pues quien escribe esa cacografía lo hace con una letra hermosa donde las haya, utiliza un lenguaje extraordinariamente culto y era, en definitiva, hombre muy familiarizado con el oficio de la escribanía. Lo dicho puede trasladarse sin demasiadas matizaciones al autor del esesivos 'excesivos' del doc. VII.

Mas es evidente que igual estado de cosas se verifica en muchos otros corpus de lengua escrita, lo mismo antiguos que modernos, aunque por tratar ahora de cuestiones históricas traeré a colación el memorial redactado entre 1495 y 1498 por el doctor Francisco de Cisneros, vecino de Sevilla, en el cual, aun cargado de erudición y cultísimamente expresado como está, sobresaldrá un catagineses al lado de otro correcto cartagineses, junto a dos clarísimas elisiones de $-s$ en "amadores de la letras" y "tanto más se requiere ingenio que non fuerça en las armas, y en esta fueron los vuestros vasallos tan exçellentes ...". Con todo, pondré de relieve la circunstancia de que, aun distinguiendo en la escritura - sin duda como algo aprendido - los usos tradicionales de $c$ y z, sin embargo alternará Cáliz con Cális y topaçios con 
topasios, y hablará de la isla llamada Topasia ${ }^{96}$. Pero, tomadas estas documentaciones en el contexto sociocultural donde verdaderamente se insertan, con ser pocas se revisten de una importancia que las hace equiparables a las que en incontenible número fluyen de fuentes con acusada caracterización vulgar ${ }^{\text {} 7}$.

4.3.3. El cotejo de las diversas formas recogidas en este estudio, incluidas las del memorial de doctor Cisneros, permite asegurar que en ellas el empleo de la ese "sigma" en modo alguno es fonéticamente operativo, como no lo era desde mucho antes. No sólo esto es así, sino que en relación muy directa con lo que afirmo está el hecho de la indistinción entre $s s$ y $s$ que afecta a no pocos documentos indianos de los dos grupos en que los he dividido atendiendo al manejo de las grafías $s$ y $c-z$, sin que para dicha igualación ortográfica importe la procedencia regional de los distintos amanuenses, y el mismo fenómeno se comprueba en el corpus del sevillano doctor Cisneros, quien únicamente recurre al signo ss en la palabra exçelsso, mientras que vasallo lo pondrá con la susodicha ese "sigma" e imperfectos de subjuntivo como fablase, fuese o pudiese con una esbeltísima y solitaria ese alta. Por supuesto que me complazco en hacer un particular ofrecimiento de todas estas menciones históricas al profesor Pascual, el cual, sin rechazar taxativamente la asendereada propuesta de un origen norteño (o "cantábrico") para el reajuste fonológico, parece inclinarse a situar la geografía del cambio "en territorios leoneses, aragoneses y mozárabes sobre los que se extendió el castellano desde el siglo XII" ${ }^{88}$, aunque, eso sí, como hipótesis "absolutamente provisional". Y tanto.

Pues bien, de una parte, debo manifestarme en el sentido de que el conjunto de la información documental expuesta en lo que precede va en contra de que el paso del consonantismo antiguo al moderno se haya producido inicialmente en el reducto del más viejo castellano, a la vez que modifica importantes aspectos de la cronología con que el problema de fonología diacrónica se ha encarado. De otra parte, de toda esa documentación se desprende que el seseo, quién sabe si también el ceceo, tenía hondas y extendidas raíces

96 Memorial de Zamora sobre las Indias, con estudio y transcripción de Demetrio Ramos Pérez, Fundación Ramos de Castro para el estudio y promoción del hombre (Zamora), Excma. Diputación Provincial de Granada, Valladolid, Gráficas Lafalpoo, 1982. Esta publicación contiene la reproducción facsímil de los dos folios del texto original.

97 Por el momento creo que será suficientemente probatorio de lo que digo el acervo documental citado más arriba, que no constituye sino una mínima parte en el conjunto de las papeletas que sobre el seseo andaluz y americano tengo recogidas.

08 José A. Pascual, "Notas sobre las confusiones medievales de las sibilantes", $L E A, \mathrm{X} / 1,1988$, pág. 129. Mi réplica a este artículo se verá próximamente en la misma revista en que ha aparecido. 
en América al mediar el siglo xvI, si bien la modalidad fonética unificadora se daba en coexistencia social con la doble solución a partir de los dos pares de sibilantes medievales $/ \mathrm{s}, \mathrm{z} / \mathrm{y} / \hat{\mathrm{s}}, \hat{\mathrm{z}} /{ }^{\circ 0}$. El proceso posterior sería de índole estrictamente sociolingüística - lucha entre dos normas diferentes, confundiciora la una, distinguidora la otra, con triunfo final de la primera-, interpretación que opino corresponde también a Guitarte, el cual, aludiendo a la situación hispanoamericana de comienzos del xix, habla de "los últimos pasos de la pérdida de una distinción fonológica" 100.

4.4. A modo de apretado resumen reiteraré brevemente mis ideas sobre algunas cuestiones previamente tratadas. En primer lugar, la de que no es aventurado suponer que muchos de los que hacia 1550 forjan en el Nuevo Mundo escritos con alteraciones de lo establecido para el uso de $s$ y $c$ - $z$ hubieran marchado de España con el correspondiente hábito fonético asimilado en su habla durante los primeros años de esta centuria, y que, para mayor abundamiento, en la inmensa mayoría de los casos su lugar de nacimiento hubo de ser Andalucía. No creo que quepan ya demasiadas dudas acerca de la decisiva influencia ejercida en el español de América por los hablantes andaluces, ni pienso que sea posible sostener por más tiempo la aseveración de Catalán de que las confusiones meridionales entre $c$ y $z$ de finales del xvi hayan de entenderse "como un resultado natural de la penetración en el andaluz del sistema madrileño" ${ }^{101}$. Ni que decir tiene, habrá que contar asimismo con la minoría de vasconavarros seseantes -recuérdese aquel sesárea debido al escribano Martín de Aranguren (doc. VI) - ${ }^{102}$, amén de los que,

98 Los datos documentales que aquí manejo no me permiten discernir cuándo indican seseo y cuándo ceceo. Si por lo general me refiero al primer modismo es porque se trata del fenómeno probablemente más antiguo, porque es el que siempre ha gozado de mayor predicamento social a ambas orillas del Atlántico, y porque es el que más extendido se halla en el continente americano, aunque también es muy posible que hunda sus raíces en el siglo xvi el ceceo que en este dominio se registra, o que al menos a algunas de sus áreas corresponda dicha cronología, sabiento además que la modalidad ceceosa tiene en tierras americanas una difusión bastante más amplia y repartida de lo que suele pensarse, cuestión para la que puede consultarse a Germán de Granda en sus "Puntos sobre algunas íes en torno al español atlántico", Amuario de Lingüistica Hispánica, III, 1987, págs. 35-54.

100 Guillermo L. Guitarte, "Seseo y distinción $s-z$ en América durante el siglo xix", Sietc estudios sobre el español de América, pág. 107.

101 D. Catalán, "El fin del fonema /z/ en español", Introducción plural a la Gramática Histórica, pág. 124.

102 Un planteamiento general de este pequeño enigma histórico hace M. ${ }^{a}$ Teresa Echenique Elizondo en "Vascos y vascuence en el proceso lingüístico nivelador del español americano", Actas del I Congreso Internacional sobre el Español de América, 
emigrados desde otras áreas peninsulares, se contagiaron del seseo después de pasar largos trechos de sus vidas en las Indias.

Con anterioridad he hecho algunas consideraciones, siquiera sea de pasada, a este problema, espinoso como ninguno, bajo el cual se esconde un factor de la constitución del español de América sumamente difícil de calibrar en su alcance real. Fontanella de Weinberg se refiere a siete peninsulares de regiones no seseantes, y recuerda ejemplos similares aducidos por Olga Cock, que en sus escritos indianos muestran ciertas confusiones de sibilantes, entre los cuales menciona al navarro Antonio de Ascona Imberto (¿de lengua materna vasca o castellana?), llegando esta investigadora a la conclusión de que "nuestro material corrobora que el medio americano, cuyo rasgo fundamental debió ser el multidialectalismo, ocasionó la erosión de los contrastes de sibilantes en muchos hablantes procedentes de zonas distinguidoras" ${ }^{103}$. Por mi parte recogeré estas tres apreciaciones, que en modo alguno quieren rechazar lo dicho por la excelente estudiosa argentina: a) sólo el análisis de textos autógrafos autoriza a advertir cambios en la norma fonética de cada hablante; $b$ ) la sustitución de un modismo por otro siempre debió ser más corriente en los descendientes criollos de los españoles trasladados a América que en estos mismos ; c) por lo que atañe al condicionamiento lingüístico de tal trasposición normativa en beneficio del seseo, tal vez resultara más fácil mientras existió una oposición fonológica $/ \dot{\mathrm{s}} / \sim / \mathrm{s} /$ derivada de $/ \mathrm{s}, \mathrm{z} / \mathrm{y} / \hat{\mathrm{s}}, \hat{\mathrm{z}} /$ que cuando se alcanzó la solución $/ \mathrm{s} / \sim / \boldsymbol{\theta} /$.

Finalmente, me reafirmo en mi creencia de que en los albores del siglo XVI en Andalucía occidental había modalidades dialectales diferenciadas del castellano siglos atrás implantado en la Bética, con rasgos fonéticos iguales o muy próximos a los hoy vigentes, y con difusión social bastante mayor de lo que a primera vista pudiera parecer, lo cual no significa que un sistena medieval $\longrightarrow$, mejor quizá, un sistema intermedio entre el medieval y el moderno- no tuviera posibilidades de pervivencia en determinados medios de la comunidad andaluza, y aun no sé si en algunos hablantes no se produciría la interferencia de normas y sistemas. Pero esto no es cosa que haya de verse como exclusiva del seseo-ceceo, pues por un precioso pasaje del sevillano Antonio del Corro sabemos que entre 1527, año de su nacimiento, y 1557, que es el de su exilio, en España convivian una pronunciación palatal y otra

págs. 269-274. A través de testimonios como el que aquí aduzco puede rastrearse la impronta vasca en la fundamentación del español de América, que habrá de situarse sin exageraciones en sus justos términos y en el muy segundo plano que seguramente le corresponde, habida cuenta, además, para calibrar bien el alcance de la documentación que al respecto pueda allegarse, que proporcionalmente fueron muchos los escribanos de oficio vascongados con destino en las diferentes Audiencias indianas.

103 María Beatriz Fontanella de Weinberg, El español bonaerense, pág. 19. 
velar de la letra $g$, de acuerdo con lo que entiendo de su enseñanza: "quando se juntare la $g$ con $e$, suena $h e, g i$, y no gue, gui, así como gesto, gentileza ...", para más adelante notar que si los franceses quieren pronunciar bien la $x$ española, "es menester que le den el sonido que comúnmente suelen dar a la letra $c h "{ }^{104 .}$

104 Antonio del Corro, Reglas gramaticales para aprender la lengua española $y$ francesa, estudio y edición de Lidio Nieto, Madrid, Arco Libros, 1988, págs. 7, 11 del facsímil. Tal vez el gramático se esté dejando guiar por lo que le dicta su conciencia lingüística de andaluz, aunque bien puede reflejar su conocimiento de una pronunciación minoritaria en el conjunto de España, y a mediados del xvi creo que había de ser la de carácter palatal, al lado de la innovación ya predominante. Quedaría por compaginar lo que dice de la letra $g$ con lo que afirma de la $x$, pero contradicciones como ésta son frecuentes en los tratadistas de la época, y en el propio Antonio del Corro se contrapone abiertamente la diferenciación fonética que establece entre $s s-s$ y $c-s$ con casos como los de jusgado o disiendo que deja pasar en su texto (págs. 5,11 ). 